\title{
Dissolvable Microneedles Coupled with Nanofiber Dressings Eradicate Biofilms via Effectively Delivering a Database Designed Antimicrobial Peptide
}

\author{
Yajuan Su${ }^{\dagger}$, Valerio Luca Mainardi ${ }^{\#}$, Hongjun Wang ${ }^{\dagger}$, Yu Shrike Zhang ${ }^{\#}$, Shixuan Chen ${ }^{\dagger}$, \\ Johnson V. John ${ }^{\dagger}$, Shannon L. Wong ${ }^{\ddagger}$, Ronald R. Hollins ${ }^{\ddagger}$, Guangshun Wang ${ }^{\zeta,}{ }^{*}$, Jingwei \\ $\mathrm{Xie}^{\dagger, *}$ \\ †Department of Surgery-Transplant and Mary \& Dick Holland Regenerative Medicine Program, \\ University of Nebraska Medical Center, Omaha, Nebraska 68130, United States \\ \#Division of Engineering in Medicine, Department of Medicine, Brigham and Women's Hospital, \\ Harvard Medical School, Cambridge, MA 02139, United States \\ 敋partment of Surgery-Plastic Surgery, University of Nebraska Medical Center, Omaha, \\ Nebraska 68130, United States
}

SDepartment of Pathology and Microbiology, College of Medicine, University of Nebraska Medical Center, University of Nebraska Medical Center, Omaha, Nebraska 68198, United States

\begin{abstract}
Biofilms in chronic wounds, including diabetic foot ulcers, pressure ulcers, and venous leg ulcers, pose a major challenge to wound management. Herein, we report a Janus-type antimicrobial dressing for eradication of biofilms in chronic wounds. The dressing consists of electrospun nanofiber membranes coupled with dissolvable microneedle arrays to enable effective delivery of a database designed antimicrobial peptide to both inside and outside biofilms. This antimicrobial dressing exhibited high efficacy against a broad spectrum of resistant pathogens in vitro. Importantly, such a dressing was able to eradicate methicillin-resistant Staphylococcus aureus (MRSA) biofilms in both an ex vivo human skin wound infection model and a type II diabetic mouse wound infection model after daily treatment without applying surgical debridement. Most
\end{abstract}

\footnotetext{
*Corresponding Authors: To whom correspondence should be addressed. jingwei.xie@unmc.edu (J. Xie) and gwang@unmc.edu (G. Wang), Phone: +1 (402) 5599442, Fax: +1(402) 5597521.

ASSOCIATED CONTENT

The Supporting Information is available free charge at ACS Publication website.

Supporting Information

Experiment methods for microneedle dissolution and FITC-dextran distribution; Schematic illustrating co-axial electrospinning and preparation of pluronic F127/W379-PCL nanofiber membranes; Schematic illustrating electrospray deposition of engineered peptide W379 to pluronic F127/W379-PCL nanofiber membranes to form pluronic F127/W379-PCL-S nanofiber membranes. SEM images of fabricated nanofiber membranes; In vitro release profiles of W379 peptide from F127/W379-PCL core-shell nanofibers and after electrospray deposition of W379; In vitro antibacterial efficacy test of F127/W379-PCL core-shell nanofibers; In vitro cytotoxicity test of W379 peptide-loaded PCL nanofiber membranes; In vivo antibiofilm efficacy test of F127/W379-PCL-S nanofiber membranes; In vitro antibacterial activity; SEM images of biofilms formed on the excisional wounds created in human skin explants; Quantification of bacteria biofilms on excisional wounds in human skin explants; Quantification of bacterial load in the diabetic wound after $24 \mathrm{~h}$ and $48 \mathrm{~h}$ of MRSA inoculation and subsequent $24 \mathrm{~h}$ of $2 \%$ mupirocin treatment; microneedle dissolution test; FITC-dextran distribution visualization (PDF)

Videos S1-S12: Animations of the peptide diffusion in the biofilm layer over time for the control and microneedle patch (MP4)

The authors declare no competing financial interest.
} 
importantly, the dressing can also completely remove the Pseudomonas aeruginosa and MRSA, dual-species biofilm in an ex vivo human skin infection model. In addition, our computational simulations also suggested that microneedles were more effective in the delivery of peptides to the biofilms than free drugs. Our results indicate that the Janus-type antimicrobial dressings may provide an effective treatment and management of chronic wound polymicrobial infections.

\section{Graphical Abstract}

\section{A Janus-Type dressing consisting of dissolvable microneedles and electrospun nanofibers} was developed for effectively delivering a database designed, LL-37-derived antimicrobial peptide to both inside and outside biofilms. The antimicrobial dressings were not only able to eradicate methicillin-resistant Staphylococcus aureus (MRSA) biofilms in a type II diabetic mouse wound infection model after daily treatment without surgical debridement but also completely remove the $P$. aeruginosa/MRSA blend biofilm in an ex vivo human skin infection model. Our results indicate the Janus-type antimicrobial dressings can provide an effective treatment and management of chronic wound polymicrobial infections.

\section{Keywords}

Janus-type dressing; nanofiber; microneedle; antimicrobial peptide; biofilm; chronic wound

Chronic wounds such as diabetic foot ulcers are a worldwide health problem. ${ }^{1,2}$ About $78 \%$ of chronic wounds contain biofilms, where a pathogenic bacterial community is encased in a biopolymer layer. ${ }^{3}$ Bacteria in biofilms are more likely to cooperate and exchange their genes resulting in much higher antibiotic resistance than planktonic bacteria. ${ }^{4,5}$ The composition and organization of biofilms limit diffusion of molecules, including antibiotics, through the structure and into the biofilm or out to the bulk fluid. ${ }^{6}$ Consequently, bacteria in a biofilm are refractory to host response and antibiotic treatment. ${ }^{7,8}$ Sharp debridement is currently the standard care to remove biofilms. ${ }^{9}$ However, vigorous and repeated debridement causes extreme discomfort to patients. This method may not be able to get rid of the biofilms completely even by removing an excessive amount of tissues. The poor treatment outcomes result in high healthcare cost, amputations, a decreased quality of life, and an increased mortality. ${ }^{10}$ There is an urgent need to develop better therapies for effective treatment of biofilms in chronic wounds.

Recent studies have been devoted to the development of various technologies for combating biofilms through enhancing drug diffusion and efficacy and other physical approaches. ${ }^{11-14}$ For examples, the surface of a surgical implant was homogeneously coated with gold nanorods designed to efficiently convert near-infrared light into heat for elimination of attached bacteria. ${ }^{11}$ This approach requires the coating of gold nanorods, which is not suitable for treatment of biofilms in chronic wounds. In a different study, to improve drug diffusion and efficacy, cationic gold nanoparticles were dispersed in the biofilms and laser was used to induce vapor nanobubbles formed around the plasmonic nanoparticles which could disrupt the biofilms and enhance the diffusion of drugs. ${ }^{12}$ This method requires the dispersion of gold nanoparticles in the biofilms, which is impossible to realize for the biofilms formed in chronic wounds. The heat generated locally could also cause further 
negative effects to the tissues in the wound area. Similarly, magnetic nanoparticles were used to create artificial channels in biofilms for enhancing bacterial killing by antibiotics. ${ }^{13}$ This method also requires the precise control of magnetic nanoparticle movement within biofilms, which might be challenging in chronic wounds. In addition, all these studies require complicated equipment such as laser or magnet and additional training. Microneedle patches were also reported recently to treat bacterial biofilms. ${ }^{14,15}$ Besides, microneedle arrays either incorporated with photothermal molecules or made of biomaterials with antibacterial property were also examined aiming for treatment of infected wounds. ${ }^{16-18}$ However, these technologies are in the early developmental stage. Most of these studies were limited to the use of traditional antibiotics which may be not effective for the treatment of antibiotic-resistant bacteria. These studies only tested the in vitro efficacy against monomicrobial biofilms which are different from the polymicrobial biofilms often encountered in chronic wounds. The in vivo and ex vivo efficacies have not been examined yet. Some of the patches cannot provide sustained release of antimicrobial agents and lack the capability in serving as scaffolds and enhancing cellular infiltration for wound healing.

Toward this end, we aimed to develop an approach to combating biofilms in chronic wounds. Our design includes two key innovations: $i$ ) development of database designed antimicrobial peptides; and ii) development of a Janus-type system for delivery of the engineered peptides. The significance of antimicrobial peptides is that they remain potent for millions of years. ${ }^{19}$ In humans, there are several dozen defensins, but only one cathelicidin gene that encodes LL-37. ${ }^{20}$ Because this native peptide has shortcomings such as the long sequence (high cost) and the instability to proteases (loss of activity), we have engineered LL-37 into 17BIPHE2 which is superior to the parent molecule in numerous aspects, such as antibiofilm and antimicrobial robustness under different salts, $\mathrm{pH}$, and media conditions. ${ }^{21-24}$ Engineered peptides exhibit a broad-spectrum activity against medically significant ESKAPE pathogens, which include Enterococcus faecium, Staphylococcus aureus, Klebsiella pneumoniae ( $K$. pneumoniae), Acinetobacter baumannii (A. baumannii), Pseudomonas aeruginosa ( $P$. aeruginosa), and Enterobacter species. We found that 17BIPHE2-containing nanofiber membranes led to a five-log colony-forming unit (CFU) decrease of methicillin-resistant Staphylococcus aureus (MRSA) USA300 LAC in a biofilm-containing chronic wound model based on type 2 diabetic mice. ${ }^{25}$ In combination with sharp debridement, a clinically viable approach for wound management, no bacteria were observed for the biofilmcontaining chronic wounds after daily treatment with peptide-loaded nanofibers for three to seven days.

Human cathelicidin LL-37 has a classic amphipathic helical structure (Figure 1, model A) in complex with bacterial membranes or mimics. ${ }^{26} \mathrm{~A}$ similar amphipathic structure can be applied to hundreds of natural peptides registered in the antimicrobial peptide database (http://aps.unmc.edu/AP). ${ }^{27}$ Based on this database, we recently discovered that low cationicity is important for in vivo efficacy of database-designed peptides. ${ }^{28}$ Inspired by this discovery and based on the antimicrobial peptide database, we have accordingly designed an entirely different peptide (W379) that forms an amphipathic structure vertically with basic charged amino acids at the top and hydrophobic domain at the bottom (Figure 1, model B). ${ }^{29}$ Such a structure led to a name verine for W379. Because this peptide is very short with merely eight amino acids (sequence: $R R R W W W W V$ ), it was chosen to be incorporated into 
electrospun nanofibers and dissolvable microneedles to form Janus-type dressings in this study. The peptide mechanism of action against multidrug resistant gram-positive and gramnegative bacteria were reported in our most recent study. ${ }^{29}$ This engineered antimicrobial peptide holds broad-spectrum antimicrobial capacity which were effective against both gram-positive and gram-negative bacteria. Based on membrane permeation and depolarization experiments, W379 could target the cell membranes of both Gram-positive and Gram-negative bacteria, leading to bacterial death. Consistent with these experiments, solid-state NMR also supports pore formation on a lipid bilayer. The membrane damage could be observed by scanning electron microscopy (SEM). Bacteria showed the smooth surface without treatment. In contrast, the bacteria membranes were entirely damaged after W379 treatment at twice the minimal inhibitory concentration (MIC). ${ }^{29}$

Microneedles have been mainly used for the transdermal drug delivery as they can assist the delivery of drugs by direct penetration through the stratum corneum and/or the epidermis. ${ }^{30-32}$ In addition, microneedles have also been used in other tissues including internal surface of mouth, vagina, gastrointestinal tract, and vascular wall and external surface of skin, eye, fingernail, and scalp. ${ }^{33}$ Inspired by these studies, we hypothesized that the dissolvable microneedle arrays containing the engineered peptides can overcome the physical barrier of biofilms, allowing the peptide to better penetrate and disrupt biofilms. To test this hypothesis, we developed a Janus-type antimicrobial dressing by immobilizing W379 peptide-incorporated microneedle arrays to the surface of peptide-encapsulated nanofiber membranes (Figure 2). We named our wound dressing as Janus-type structure as it had a two-side/biphasic structure and each side showed different functions. The immobilized microneedle arrays could penetrate into biofilms and deliver peptides to the inside biofilms to disrupt the biofilms. Simultaneously, the nanofiber membranes could provide a sustained release of peptides to the outside biofilms to attack bacterial biofilms. The dual actions of our antibiofilm Janus-type dressing may contribute to the removal of biofilms and eventually prevent the resurgence of bacteria. In addition, electrospun nanofiber membranes could serve as a physical barrier between the wound bed and the surrounding environment. The nanofiber membranes could also serve as a scaffold for promoting wound healing after eradication of biofilms. We chose poly( $\varepsilon$-caprolactone) (PCL), a biodegradable polyester, as raw materials for fabrication of nanofiber membranes as PCL has been used for making medical devices approved by the United States Food and Drug Administration (FDA). ${ }^{34} \mathrm{We}$ chose polyvinylpyrrolidone (PVP) as the raw materials for fabrication of the dissolvable microneedle arrays due to its water-soluble property and its FDA approval for use as an inactive ingredient. ${ }^{35}$

\section{RESULTS AND DISCUSSION}

\section{Preparation and Characterization of Peptide-Incorporated Nanofiber Membranes.}

Prior to fabrication of the Janus-type antimicrobial dressing, we first prepared the peptideloaded nanofibers by co-axial electrospinning and electrospray deposition techniques by following our previous studies as illustrated in Figure S1. ${ }^{25}$ Figure S2A shows a photo of the F127/W379-PCL nanofiber membrane. Figure S2, B-D, shows the SEM images of F127PCL, F127/W379-PCL and F127/W379-PCL-S nanofiber samples, indicating that all the 
samples exhibited a fibrous and porous structure. Note that the fibrous and porous structure could act as extracellular matrix (ECM)-mimicking scaffolds serving as an artificial ECM suitable for wound healing. Moreover, the core-shell structure could protect the encapsulated biological agents from a hostile microenvironment. The encapsulation efficiencies of W379 in the F127/W379-PCL and F127/W379-PCL-S nanofiber samples were 94.3 $\pm 3.3 \%$ and $90.7 \pm 2.7 \%$, respectively. The amount of W379 incorporated into the F127/W379-PCL and F127/W379-PCL-S nanofiber samples were $23.58 \pm 0.83$ and $45.35 \pm 1.35 \mathrm{mg} / \mathrm{g}$. After electrospray deposition of the peptides, the encapsulation efficiency decreased, probably due to the loss of some amount of the aggregated drug during the electrospray deposition. Figure S3 shows the in vitro release kinetics of the W379 peptides from the F127/W379-PCL and F127/W379-PCL-S nanofiber samples, suggesting a burst release followed by a sustained release over 28 days. A sustained release of the peptides could be critical to prevent the recurrence of infection or biofilm formation.

We further evaluated the in vitro antibacterial efficacy of peptides-loaded nanofiber membranes. Four pathogens including MRSA USA300, K. pneumoniae, A. baumannii and $P$. aeruginosa were applied to determine the in vitro antibacterial activities of the peptidesloaded nanofiber membranes. As shown in Figure S4, the F127/W379-PCL core-shell nanofibers effectively killed the four typical infection-related bacterial strains, with 5.0, 5.1, 5.4, and 5.4-log reduction of MRSA USA300, $K$. pneumoniae, $A$. baumannii, and $P$. aeruginosa, respectively. Moreover, the F127/W379-PCL-S nanofibers also effectively killed the bacteria clinical strains in vitro, with 5.6, 5.5, 5.7, and 5.8-log reduction of MRSA USA300, K. pneumoniae, A. baumannii and $P$. aeruginosa, respectively (Figure S4). Interestingly, the peptide-loaded PCL nanofibers ( $\triangle \mathrm{mg} / \mathrm{mL}$ ) had no significant influences on the proliferation of skin cells, including keratinocytes and dermal fibroblasts (Figure S5). Thus, at this concentration $(1 \mathrm{mg} / \mathrm{mL})$, the W379 peptide-loaded nanofibers were effective to kill the bacteria but not skin cells (Figure S4). Furthermore, our in vivo test showed about 5magnitude reduction of CFU after 3 membrane changes in 3 days (Figure S6A). In combination with debridement, no MRSA bacteria were detected after 3 membrane changes in 3 days. Similarly, our in vivo test also showed about 5-log reduction of CFU after 7 membrane changes in 7 days (Figure S6B). In combination with debridement, no MRSA USA300 bacteria were detected after 7 membrane changes in 7 days. These results indicated that the W379 peptides showed an antimicrobial activity similar to 17BIPHE2. ${ }^{25}$ However, the sharp debridement was still necessary to combine with peptide-loaded nanofiber membranes to eradicate the biofilms. We speculated that the penetration of the antimicrobial peptides into the biofilms could be the major obstacle.

\section{Preparation of Janus-Type Dressings and Their Antimicrobial Efficacy In Vitro.}

To overcome this problem, we developed a Janus-type antimicrobial dressing (Figure 3A). Figure 3, B and D, shows the W379 peptide-loaded PVP microneedle arrays with two different densities (100 microneedles per membrane and 150 microneedles per membrane). Figure 3C shows a SEM image of the bottom substrate indicating the nanofibrous morphology. We then tested the in vitro antibacterial activity of the Janus-type dressings. Compared to the F127-PCL core-shell nanofibers and the W379/F127-PCL core-shell nanofibers alone, the Janus-type dressing, consisting of W379/F127-PCL core-shell 
nanofibers and W379-loaded PVP microneedles, showed larger CFU reductions of MRSA USA300, K. pneumoniae, $A$. baumannii, and $P$. aeruginosa (Figure S7).

\section{Efficacy of Janus-type Dressings against Biofilms Ex Vivo.}

To assess the efficacy against biofilms, we established a biofilm-containing human skin wound model using different pathogens. Figure S8, A-C, shows SEM images of the morphology of $A$. baumannii P. aeruginosa, and MRSA USA300 biofilms on the excisional wounds in human skin explants. The CFUs of different biofilms $\left(10^{10}-10^{12} \mathrm{CFU} / \mathrm{g}\right)$ formed after bacteria inoculation for 3 days were quantified as shown in Figure S8D. We then tested the efficacy of Janus-type antimicrobial dressings in eliminating biofilms in the excisional wounds created in human skin explants. We applied different dressings to the biofilmcontaining wounds for $24 \mathrm{~h}$ and conducted CFU counting. The treatment with PCL-F127/ W379+PVP/W379 MN dressings showed the best performance (5.67-, 5.82-, and 6.14-Log reductions, respectively) against $A$. baumannii, $P$. aeruginosa, and MRSA USA300 biofilms among all the treatment groups (Figure 4A). It is worth mentioning that compared with PCL-F127/379+aqueous W379 treatment, the administration of PCL-F127/W379+PVP/ W379 MN with the same peptide dose showed a significant reduction (3.44-, 2.79-, and 3.25-Log against $A$. baumannii, P. aeruginosa, and MRSA USA300, respectively) in CFU counting (Figure 4A). This result indicated that the dissolvable microneedle arrays were critical in the delivery of engineered peptides to the inside of biofilms due to their direct physical penetration. To completely get rid of the biofilms without debridement, we changed the dressings daily for 3 days and we found that the MRSA biofilms were eradicated after 3 changes (Figure 4B). In contrast, there were still about $8.91 \times 10^{4} \mathrm{CFU} / \mathrm{g}$ bacteria remaining on the wounds treated by peptide-loaded nanofiber membranes alone with and without incorporation of aqueous peptides even after 3 changes (Figure 4B). This result further confirmed the importance of the microneedles for effective delivery of our engineered peptides to treat biofilms. To enhance the anti-biofilm efficacy, we increased the peptide loading in the microneedle arrays from $25 \mathrm{mg} / \mathrm{g}$ to $50 \mathrm{mg} / \mathrm{g}$. However, the increased dose showed a similar anti-biofilm efficacy, with both of the two dressings needing 3 changes, suggesting doubling the peptide loading resulted in marginal enhancement in the bacteria killing in biofilms. We further increased the density of microneedles on the surface from 100 to 150 microneedles per nanofiber membrane at the same dose $(25 \mathrm{mg} / \mathrm{g})$ as shown in Figure 3 , B and D. Interestingly, we did not detect the bacteria after changing the Janus-type antimicrobial dressing twice and 3 times (Figure 4D). Similarly, there were still about $8.72 \times 10^{4} \mathrm{CFU} / \mathrm{g}$ bacteria remaining on the wounds treated by the peptide-loaded nanofiber membranes alone with and without incorporation of the peptide solution even after 2 and 3 changes (Figure 4D). This result indicated that reducing the distance between the adjacent microneedles could promote the anti-biofilm efficacy, likely due to the increase of the peptide diffusion area.

\section{Efficacy of Janus-Type Dressings against MRSA Biofilms In Vivo.}

To further evaluate the anti-biofilm efficacy, we established MRSA biofilms in type II diabetic mouse wounds following previous studies (Figure 5A-C). Briefly, wounds were created and fixed with a splint. Ten $\mu \mathrm{L}$ of $10^{8} \mathrm{CFU} / \mathrm{mL}$ MRSA was inoculated to each wound for $24 \mathrm{~h}$ and $48 \mathrm{~h}$ and followed by $24 \mathrm{~h}$ treatment of $2 \%$ mupirocin ointment to 
remove the planktonic bacteria on the wounds. The CFUs of MRSA biofilms $\left(10^{10}-10^{12}\right.$ $\mathrm{CFU} / \mathrm{g}$ ) formed after $24 \mathrm{~h}$ and $48 \mathrm{~h}$ of bacteria inoculation and removal of planktonic bacteria were quantified as shown in Figure S9. The biofilm formation was confirmed by live/dead staining and SEM observation for the tissues collected from the wounds after $24 \mathrm{~h}$ of MRSA inoculation and subsequent $24 \mathrm{~h}$ of $2 \%$ mupirocin treatment (Figure 5, B and C). For in vivo anti-biofilm testing, we applied Janus-type dressings with and without loading engineered peptides and peptides-loaded nanofibers plus aqueous peptides to the biofilmcontaining wounds. After 3 changes ( 1 change per $24 \mathrm{~h}$ ), there were $7.76 \times 10^{10} \mathrm{CFU} / \mathrm{g}$ in the tissues collected from the wounds treated by Janus-type dressings without the peptide loading. The treatment with the F127/379-PCL core-shell nanofibers plus aqueous peptides resulted in 6-Log reduction of CFU/g. Very importantly, consistent with the ex vivo results, no bacteria were detected on the wounds treated by Janus-type dressings consisting of both the F127/379-PCL core-shell nanofiber membranes and the W379-loaded PVP microneedle arrays (Figure 5D). This result indicated that the Janus-type antimicrobial dressings were also effective against biofilms in vivo.

\section{Efficacy of Janus-Type Dressings against MRSA and P. aeruginosa, Dual-Species Biofilms Ex Vivo.}

It is known that the chronic wound infection/biofilm in clinics is much more complicated and is often involved with more than one type of germ. ${ }^{36,37}$ To more closely mimic the clinical scenario, we established a $P$. aeruginosa/MRSA blend biofilm in an ex vivo human skin model and the anti-biofilm efficacy was determined by changing the dressings every 24 h. To confirm the formation of the blend biofilm, the collected tissues were cut into slices and Gram staining was performed to distinguish the Gram+ and Gram- bacteria. $P$. aeruginosa was stained in red, and MRSA was stained in violet (Figure 6A). The SEM observation further confirmed the existence of both rod-shaped and round-shape bacteria, which were assigned to $P$. aeruginosa and MRSA, respectively (Figure 6B). In addition, during the CFU-counting process, we detected two types of bacteria colonies. Some colonies were smaller in golden or yellow color which were MRSA, and the other colonies were larger with a lighter color which were $P$. aeruginosa (Figure 6C). After, we successfully established the blend biofilm in an ex vivo model. Then, different treatments were applied to manage this biofilm. Among them, Janus-type dressing treatment showed the best efficacy based on the CFU reduction and no colonies were detected after 3 changes of the dressings (Figure 6D). This result was very significant as it indicated that our Janus-type dressing could be effective in the management of polymicrobial biofilms in chronic wounds.

In this study, the conical microneedles were made from PVP, a water-soluble matrix. After administration of Janus-type dressings, the peptides-containing PVP microneedles dissolved within 3 min upon penetration into the biofilm and the peptides were then diffused into the surrounding areas inside the biofilm, which mainly contributed to the effective removal of biofilms (Figure S10). Fluorescein isothiocyanate (FITC-dextran) was incorporated to microneedle arrays which were administrated to biofilms in human skin wounds ex vivo, further revealing FITC-dextran can effectively diffuse to the surrounding regions within biofilms (Figure S11). Simultaneously, the electrospun nanofiber membranes eluted peptides to the external areas of the biofilms with an initial burst followed by a sustained release. The 
released peptides at the initial stage could diffuse into the biofilm and partly contribute to the eradication of the biofilm. The peptides released in a sustained manner at later stages could prevent the recurrence of infection and biofilm formation. Overall, it is expected that the Janus-type antimicrobial dressings showed a large burst release followed by a sustained release, which was mainly attributed to the dissolution of microneedles and slow elution from electrospun nanofibers, respectively.

\section{Computational Simulations of Peptide Delivery for Comparing Microneedle Patches with Free Drugs.}

To further understand our experimental results, we performed computational simulations using COMSOL Multiphysics which allowed to evaluate the peptide diffusion within the biofilm layer over time (Figure 7). The color maps showed the peptide concentrations along the depth of the biofilm layer comparing the microneedle patch and the control (free drug). Figure 7, $\mathrm{G}$ and $\mathrm{H}$ shows the differences of the peptide concentrations towards the basis of the biofilm layer qualitatively between the two configurations at different time points ( $T=24$ $\mathrm{h}$ and $36 \mathrm{~h}$ ), and for different distances between the two adjacent microneedles ( $\mathrm{d}=150 \mu \mathrm{m}$ and $300 \mu \mathrm{m}$ ). Figure 7 , I and $\mathbf{J}$ shows the quantitative analysis of the peptide concentrations over time in the top, middle, and bottom planes which corresponded to $250 \mu \mathrm{m}, 500 \mu \mathrm{m}$, and $1000 \mu \mathrm{m}$ away from the patch base.

The molar mass of the engineered peptide in this study is $1330 \mathrm{~g} / \mathrm{mol}$. Based on the literature, ${ }^{38}$ we assumed the diffusion coefficient of peptides in the biofilm was $D=1 \times 10^{-12} \mathrm{~m}^{2} / \mathrm{s}$ in the simulation (Figure 7, G-J). In the bottom plane of the microneedle patch $(\mathrm{d}=150 \mu \mathrm{m})$, the peptide concentrations were 4.93 -fold $\left(2.96 \mathrm{~mol} / \mathrm{m}^{3}\right.$ versus (v.s.) $\left.0.60 \mathrm{~mol} / \mathrm{m}^{3}\right)$ and 3.14 -fold $\left(5.81 \mathrm{~mol} / \mathrm{m}^{3}\right.$ v.s. $\left.1.85 \mathrm{~mol} / \mathrm{m}^{3}\right)$ higher than those of the control after $24 \mathrm{~h}$ and $36 \mathrm{~h}$, while for the microneedle patch $(\mathrm{d}=300 \mu \mathrm{m})$, they were 3.41-fold $(2.05$ $\mathrm{mol} / \mathrm{m}^{3}$ v.s. $\left.0.60 \mathrm{~mol} / \mathrm{m}^{3}\right)$ and 2.39 -fold $\left(4.42 \mathrm{~mol} / \mathrm{m}^{3}\right.$ v.s. $\left.1.85 \mathrm{~mol} / \mathrm{m}^{3}\right)$ higher accordingly. In the middle plane of the microneedle patch $(\mathrm{d}=150 \mu \mathrm{m})$, the peptide concentrations were 2.62 -fold $\left(11.34 \mathrm{~mol} / \mathrm{m}^{3}\right.$ v.s. $\left.4.32 \mathrm{~mol} / \mathrm{m}^{3}\right)$ and 2.09 -fold $\left(12.98 \mathrm{~mol} / \mathrm{m}^{3}\right.$ v.s. $\left.6.20 \mathrm{~mol} / \mathrm{m}^{3}\right)$ higher than those of the control after $24 \mathrm{~h}$ and $36 \mathrm{~h}$, while for the microneedle patch $(\mathrm{d}=300$ $\mu \mathrm{m})$, they were 2.10 -fold $\left(9.07 \mathrm{~mol} / \mathrm{m}^{3}\right.$ v.s. $\left.4.32 \mathrm{~mol} / \mathrm{m}^{3}\right)$ and 1.77 -fold $\left(11.01 \mathrm{~mol} / \mathrm{m}^{3}\right.$ v.S. $\left.6.21 \mathrm{~mol} / \mathrm{m}^{3}\right)$ higher accordingly. In the top plane of the microneedle patch $(\mathrm{d}=150 \mu \mathrm{m})$, the peptide concentrations were 1.67 -fold $\left(17.21 \mathrm{~mol} / \mathrm{m}^{3}\right.$ v.s. $\left.10.32 \mathrm{~mol} / \mathrm{m}^{3}\right)$ and 1.50 -fold $\left(17.61 \mathrm{~mol} / \mathrm{m}^{3}\right.$ V.s. $\left.11.75 \mathrm{~mol} / \mathrm{m}^{3}\right)$ higher than those of the control after $24 \mathrm{~h}$ and $36 \mathrm{~h}$, while for the microneedle patch $(\mathrm{d}=300 \mu \mathrm{m})$, they were 1.49 -fold $\left(15.37 \mathrm{~mol} / \mathrm{m}^{3}\right.$ v.s. 10.32 $\left.\mathrm{mol} / \mathrm{m}^{3}\right)$ and 1.38 -fold $\left(16.21 \mathrm{~mol} / \mathrm{m}^{3}\right.$ v.s. $\left.11.75 \mathrm{~mol} / \mathrm{m}^{3}\right)$ higher accordingly.

Due to the possibility of binding with extracellular polymeric substances (EPS), irreversible sorption, and/or catalytic reaction in biofilms, the penetration of peptides could be profoundly retarded. ${ }^{39,40}$ We then considered $D=5 \times 10^{-13} \mathrm{~m}^{2} / \mathrm{s}$ in the simulation (Figure 7 G-J). In the bottom plane of the microneedle patch $(\mathrm{d}=150 \mu \mathrm{m})$, the peptide concentrations were 18.28 -fold $\left(0.51 \mathrm{~mol} / \mathrm{m}^{3}\right.$ v.s. $\left.0.03 \mathrm{~mol} / \mathrm{m}^{3}\right)$ and 7.64 -fold $\left(1.58 \mathrm{~mol} / \mathrm{m}^{3}\right.$ v.s. 0.21 $\mathrm{mol} / \mathrm{m}^{3}$ ) higher than those of the control after $24 \mathrm{~h}$ and $36 \mathrm{~h}$, while for the microneedle patch $(\mathrm{d}=300 \mu \mathrm{m})$, they were 10.84 -fold $\left(0.30 \mathrm{~mol} / \mathrm{m}^{3}\right.$ v.s. $\left.0.03 \mathrm{~mol} / \mathrm{m}^{3}\right)$ and 4.94 -fold $(1.02$ 
$\mathrm{mol} / \mathrm{m}^{3}$ v.s. $0.21 \mathrm{~mol} / \mathrm{m}^{3}$ ) higher accordingly. In the middle plane of the microneedle patch $(\mathrm{d}=150 \mu \mathrm{m})$, the peptide concentrations were 4.87 -fold $\left(8.11 \mathrm{~mol} / \mathrm{m}^{3}-1.67 \mathrm{~mol} / \mathrm{m}^{3}\right)$ and 3.25 -fold $\left(10.08 \mathrm{~mol} / \mathrm{m}^{3}-3.10 \mathrm{~mol} / \mathrm{m}^{3}\right)$ higher after $24 \mathrm{~h}$ and $36 \mathrm{~h}$, while for the microneedle patch $(\mathrm{d}=300 \mu \mathrm{m})$, they were 3.38 -fold $\left(5.63 \mathrm{~mol} / \mathrm{m}^{3}\right.$ v.s. $\left.1.67 \mathrm{~mol} / \mathrm{m}^{3}\right)$ and 2.46 -fold $\left(7.64 \mathrm{~mol} / \mathrm{m}^{3}\right.$ v.s. $\left.3.10 \mathrm{~mol} / \mathrm{m}^{3}\right)$ higher accordingly. In the top plane of the microneedle patch $(\mathrm{d}=150 \mu \mathrm{m})$, they were 2.15 -fold $\left(16.06 \mathrm{~mol} / \mathrm{m}^{3}\right.$ v.s. $\left.7.46 \mathrm{~mol} / \mathrm{m}^{3}\right)$ and 1.83 -fold $\left(16.84 \mathrm{~mol} / \mathrm{m}^{3}\right.$ v.s. $\left.9.19 \mathrm{~mol} / \mathrm{m}^{3}\right)$ higher after $24 \mathrm{~h}$ and $36 \mathrm{~h}$, while for the microneedle patch $(\mathrm{d}=300 \mu \mathrm{m})$, they were 1.77 -fold $\left(13.20 \mathrm{~mol} / \mathrm{m}^{3}\right.$ v.s. $\left.7.46 \mathrm{~mol} / \mathrm{m}^{3}\right)$ and 1.59 -fold $\left(14.60 \mathrm{~mol} / \mathrm{m}^{3}\right.$ v.s. $\left.9.19 \mathrm{~mol} / \mathrm{m}^{3}\right)$ higher correspondingly.

We also considered $D=1 \times 10^{-13} \mathrm{~m}^{2} / \mathrm{s}$ in the simulation (Figure 7, G-J). In the top plane of the microneedle patch $(\mathrm{d}=150 \mu \mathrm{m})$, the peptide concentrations were 8.57 -fold $\left(9.26 \mathrm{~mol} / \mathrm{m}^{3}\right.$ v.s. $\left.1.08 \mathrm{~mol} / \mathrm{m}^{3}\right)$ and 4.96 -fold $\left(11.28 \mathrm{~mol} / \mathrm{m}^{3}\right.$ v.s. $\left.2.28 \mathrm{~mol} / \mathrm{m}^{3}\right)$ higher than those of the control after $24 \mathrm{~h}$ and $36 \mathrm{~h}$, while for the microneedle patch $(\mathrm{d}=300 \mu \mathrm{m})$, they were 5.30fold $\left(5.72 \mathrm{~mol} / \mathrm{m}^{3}\right.$ v.s. $\left.1.08 \mathrm{~mol} / \mathrm{m}^{3}\right)$ and 3.29 -fold $\left(7.48 \mathrm{~mol} / \mathrm{m}^{3}\right.$ v.s. $\left.2.28 \mathrm{~mol} / \mathrm{m}^{3}\right)$ higher accordingly. In the middle plane of the microneedle patches, the peptide concentrations were $1.95 \mathrm{~mol} / \mathrm{m}^{3}$ and $2.91 \mathrm{~mol} / \mathrm{m}^{3}$ when $\mathrm{d}=150 \mu \mathrm{m}$ and $1.10 \mathrm{~mol} / \mathrm{m}^{3}$ and $1.66 \mathrm{~mol} / \mathrm{m}^{3}$ when $\mathrm{d}=$ $300 \mu \mathrm{m}$ after $24 \mathrm{~h}$ and $36 \mathrm{~h}$, while all the corresponding values for the control were approximately equal to $0 \mathrm{~mol} / \mathrm{m}^{3}$. Very low values (approximately $0 \mathrm{~mol} / \mathrm{m}^{3}$ ) of peptide concentrations were found for both configurations in the bottom plane. The animations of the peptide diffusion in the biofilm layer over time for different conditions were also shown in Video S1-S12.

Based on the simulation data, it is evident that the microneedle patch can provide a more effective way to deliver peptides to biofilms than free drug, consistent with our experimental results. Modulating the design of the microneedle patch such as decreasing the distance between adjacent microneedles (increasing microneedle density) could further enhance the diffusion of peptides to the biofilm, which agreed well with our experimental findings as reduction of the gap distance between microneedles enhanced the efficacy against biofilms. Importantly, based on the simulation results, we could accordingly change the administration strategy of the Janus-type antimicrobial dressing such as extending the time for the dressing change to further reduce procedures while maintaining the anti-biofilm efficacy.

Current topical and systemic antibiotics are minimally effective in the treatment of chronic biofilm infection in wounds due to the slow or incomplete penetration of antimicrobials to bacterium. ${ }^{41}$ Most of the delivery systems in the literature use nanoparticles, microparticles, microemulsions, liposomes, nanofibers, and hydrogels etc. ${ }^{42}$ However, all these delivery systems have the common problem to achieve the effective drug penetration into biofilms. In contrast, our delivery system consisted of a combination of microneedle patches and electrospun nanofiber membranes rather than traditional microneedle pads or nanofiber membranes alone. The Janus-type structure was formed through immobilization of microneedle arrays to the surface of nanofiber membranes. The immobilized microneedle arrays could penetrate biofilms and deliver database designed antimicrobial peptides to the inside biofilms and thus disrupt the biofilms. Simultaneously, the nanofiber membranes could provide a sustained release of the peptides to the outside biofilms for partially 
contributing to the removal of biofilms and eventually preventing the resurgence of bacteria. The double hit of our Janus-type wound dressings developed here could eradicate bacterial biofilms without applying any debridement. Our current design is superior to the nanofiber membrane alone we designed previously, which completely removed the biofilm only when it was combined with debridement in the diabetic mouse wounds. ${ }^{25}$

In future studies, we could also co-incorporate other types of antimicrobial agents including silver nitrate, gallium nitrate, and/or antibiotics into our Janus-type antimicrobial dressings to achieve a combinatorial or synergistic antimicrobial effect. ${ }^{41}$ We could further coincorporate other functional nanoparticles (magnetic or photothermal nanoparticles) or molecules (photothermal dyes) into microneedles to synergistically exert physical disruption of biofilms. ${ }^{42,43}$ We could also optimize the Janus-type antimicrobial dressings, including the geometric design, pattern, density, composition, and loading of engineered peptides and other antimicrobial agents in the microneedles and electrospun nanofiber membranes to further promote their anti-biofilm efficacy. In addition, our recent studies demonstrated the fabrication of different forms of 3D nanofiber scaffolds consisting of hierarchically assembled nanofibers with controlled alignment. ${ }^{44}$ The 3D nanofiber scaffolds can promote cellular infiltration to form 3D tissue constructs in vitro and in vivo. We may combine 3D nanofiber scaffolds with microneedle arrays to form Janus-type antimicrobial dressings that can not only eradicate biofilms but also promote chronic wound healing. Of note, the fabrication of electrospun nanofibers and microneedles is already a practice in industry. The described method should be readily accommodated with good manufacturing practice (GMP) facility for scale-up production of Janus-type wound dressings for translational applications.

\section{CONCLUSIONS}

In summary, we have fabricated Janus-type antimicrobial dressings and demonstrated their effective treatment of bacterial biofilms in excisional wounds in human skin explants and type II diabetic mouse wounds without debridement. Unlike classic antimicrobial peptides, the peptide in this dressing has an entirely different amphipathic model. The microneedle array appears to enhance peptide penetration for an improved efficacy. In addition, computation simulations further indicated that the microneedle patch could be more effective to deliver peptides compared to free drugs, which were in line with our experimental results. Since the peptide is very short and the dressing materials have been proven safe, the antimicrobial technology developed in this work may provide an effective intervention with great potential that could effectively treat biofilms, especially those formed by multi-drug resistant bacteria. When successfully translated to the bedside, our technology should improve quality of wound care and avoid amputations.

\section{METHODS}

Materials.

PCL $(\mathrm{Mw}=70-90 \mathrm{kDa}), \mathrm{PVP}(\mathrm{Mw}=130 \mathrm{kDa})$ and pluronic F127 were purchased from Sigma-Aldrich (St. Louis, MO). Dulbecco's modified Eagle's medium (DMEM) and RPMI 1640 medium were bought from Thermo Fisher Scientific Gibco (Waltham, MA). 
Dichloromethane (DCM) and N, N-dimethylformamide (DMF) were acquired from Thermo Fisher Scientific (Waltham, MA). The W379 antimicrobial peptide was prepared according to our previous work. MRSA USA300 LAC and A. baumannii B2367-12 were obtained from the University of Nebraska Medical Center (UNMC), while $K$. pneumoniae (ATCC 13883) and $P$. aeruginosa PAO1 were obtained from the American Type Culture Collection (ATCC). Columbia CAN with 5\% sheep blood agar medium was purchased from Remel (Lenexa, KS), and tryptic soy broth (TSB) bacterial medium was purchased from Thermo Fisher Scientific Oxoid (Waltham, MA). LIVE/DEAD BacLight bacterial viability kit and Alamar Blue cell viability assay kit were purchased from Thermo Fisher Scientific Invitrogen (Waltham, MA). Peptides (95\% pure) were purchased from GeneMed Synthesis (San Antonio, TX).

\section{Fabrication of Molecularly Engineered Peptides-Loaded Nanofibers.}

The F127/W379-PCL core-shell nanofibers were prepared by co-axial electrospinning following our previous studies. ${ }^{25}$ Briefly, a given mass of PCL was dissolved in a solvent mixture consisting of DCM and DMF with a ratio of 4:1(v/v) at a concentration of $10 \%$ PCL (w/v). To prepare the F127-PCL core-shell fibers, $1 \mathrm{~g}$ of pluronic F127 was dissolved in 10 $\mathrm{mL}$ of $\mathrm{ddH}_{2} \mathrm{O}$ to form the aqueous phase. To prepare the F127/W379-PCL core-shell fibers, $1 \mathrm{~g}$ of pluronic F127 and $25 \mathrm{mg}$ of $\mathrm{W} 379$ were dissolved in $10 \mathrm{~mL}$ of $\mathrm{ddH}_{2} \mathrm{O}$ to form the aqueous phase. The polymer phase was pumped at a flow rate of $0.5 \mathrm{~mL} / \mathrm{h}$ and the aqueous phase was pumped at a flow rate of $0.02 \mathrm{~mL} / \mathrm{h}$ while a potential of $20 \mathrm{kV}$ was applied between the spinneret (a 22-gauge needle) and a grounded collector located $12 \mathrm{~cm}$ apart from the spinneret. A rotating drum was used to collect the membranes composed of random fibers with a rotating speed lower than $100 \mathrm{rpm}$. Then, the obtained fiber samples were divided into two parts. One part was stored in $4{ }^{\circ} \mathrm{C}$ and named as F127/W379-PCL (Figure S2). The other part was coated with $10 \mathrm{mg}$ of W379 and named as F127/W379-PCL-S (Figure S2). Briefly, the W379 aqueous solution was deposited onto the fibers through electrospraying. All the fiber samples were sterilized by ethylene oxide before cell culture and in vivo animal study.

\section{Fabrication of Janus-Type Dressing.}

The fabrication of the microneedle patch was performed using a polydimethylsiloxane (PDMS) micromold (Blueacre Technology Ltd., Dundalk, Ireland) with each needle cavity being $300 \mu \mathrm{m}$ in a round-base diameter and $300 \mu \mathrm{m}$ in height. There were 100 (low density mold) or 150 (high density mold) needles on a 6-mm circular array. In brief, $50 \mu \mathrm{L}$ of a 20 wt \% PVP aqueous solution containing different concentrations of W379 antimicrobial peptide was deposited into the cavities and kept under vacuum for $10 \mathrm{~min}$. Subsequently, the F127-W379/PCL-S nanofiber mat was placed onto the micromold and allowed to dry at room temperature. After complete desiccation, the Janus-type dressing was detached from the silicone mold for further use. For the preparation of the control Janus-type dressing, no W379 was added to the F127 or PVP solution.

\section{Morphology Characterization of Janus-Type Dressing.}

The morphology of F127-W379/PCL-S nanofiber and Janus-type samples were characterized by SEM (FEI, Quanta 200, Oregon). To avoid charging, polymeric fiber 
samples were fixed on a metallic stud with a double-sided conductive tape and coated with platinum for $4 \mathrm{~min}$ in vacuum at a current intensity of $10 \mathrm{~mA}$ using a sputter coater. SEM images were acquired at an accelerating voltage of $30 \mathrm{kV}$.

\section{In Vitro Antibacterial Efficacy Test.}

The antibacterial activity of F127-W379/PCL-S nanofiber and Janus-type dressings was investigated. Single bacterial colonies of MRSA, $K$. pneumoniae, $A$. baumannii, and $P$. aeruginosa were picked up by inoculating loops and cultured at $37^{\circ} \mathrm{C}$ and $200 \mathrm{rpm}$ in liquid TSB overnight. Ten microliters of bacterial culture were added into $2 \mathrm{~mL}$ of fresh TSB and incubated for additional $2 \mathrm{~h}$. Then, the cultures were centrifuged and washed with PBS twice. Bacteria were resuspended and then diluted into $1.0 \times 10^{7} \mathrm{CFU} / \mathrm{mL}$ in PBS. One milligram each of Janus-type dressings with or without W379 loading was co-incubated with the bacterial solution for $2 \mathrm{~h}$ at $37^{\circ} \mathrm{C}$. Total living bacteria were determined by culturing on agar plates, and the log reduction of bacteria was calculated by the following equation.

$\log$ reduction $=\log ($ cell count of control $)-\log ($ survivor count in peptide treatment group $)$

\section{In Vitro Cytotoxicity Test.}

The in vitro cytotoxicity of nanofiber membranes to skin cells and monocytes was investigated by determining the cell viability of co-incubated $\mathrm{HaCaT}$ cells (human keratinocyte cell line) and U937 cells as described in the previous work. ${ }^{25}$ Nanofiber membranes were firstly sterilized by ethylene oxide. HaCaT cells were cultured in DMEM with 10\% FBS, and U937 cells were cultured in RMPI1640 with 10\% FBS. HaCat and U937 cells were seeded in 24-well plates. Each well contains $2.5 \times 10^{4}$ cells and $1 \mathrm{~mL}$ culture media. The cells were treated by the similar procedure described in the section of cell culture and treatments. The pre-sterilized slides were placed into the wells with the surface coatings contacting with the cells. The plate containing cells and slides was cultured for 5 days and the culture medium was refreshed every 2 days. On days 1,3 , and 5 , the cell viability was investigated by Alamar Blue assay.

\section{Ex Vivo Anti-Biofilm Efficacy Test.}

To evaluate the anti-bacterial and anti-biofilm efficacy ex vivo, we established a biofilmcontaining chronic wound model on human skin tissues. The human skin tissues were collected from patients who underwent plastic surgery, and the IRB protocol was approved by the University of Nebraska Medical Center. After collection, skin tissues were kept on ice. Fat tissues were removed, and the skin tissue was rinsed in PBS thrice in order to remove blood. Then, the skin tissue was cut into $2 \mathrm{~cm} \times 2 \mathrm{~cm}$. A wound was generated by an 8 -mm punch in the center of each skin fragment. The wound depth was around $1 \mathrm{~mm}$. MRSA, $A$. baumannii, and $P$. aeruginosa colonies were prepared by the same method described above. Twenty microliters of bacterial liquid at the concentration of $1 \times 10^{8}$ $\mathrm{CFU} / \mathrm{mL}$ was added to the wound. All the cultures were maintained at $37^{\circ} \mathrm{C}$ for $72 \mathrm{~h}$, Then, the surrounding and wound tissues were collected using a $10 \mathrm{~mm}$-diameter punch, and the 
biofilm formation was confirmed by CFU count, LIVE/DEAD staining, and SEM observation.

After the establishment of the biofilm, the F127/W379-PCL-S core-shell nanofiber membranes or Janus-type dressings were placed on the wounds. Different administration strategies of dressings including different antimicrobial peptide concentrations, different microneedle densities and different antimicrobial agents were applied to treat the biofilm formed wound. After treatment, the wound and surrounding tissues were collected by a 10 $\mathrm{mm}$-diameter punch and put into sterilized tubes. Then, $1 \mathrm{~mL}$ of sterilized PBS was added to each tube, which was blended by a homogenizer (Fisher Scientific, Hampton, NH).

Subsequently, the mixed liquid was diluted and plated on agar dishes. All the dishes were inoculated in a $37^{\circ} \mathrm{C}$ microbial incubator for $18 \mathrm{~h}$, and the $\mathrm{CFU}$ numbers were counted.

\section{In Vivo Anti-Biofilm Efficacy Test.}

We established a biofilm-containing chronic wound model following previous studies. ${ }^{25}$ Briefly, MRSA was grown in TSB overnight. Subsequently, $100 \mu \mathrm{L}$ of bacterial strain was pipetted into $4 \mathrm{~mL}$ of fresh TSB medium and cultivated for $3 \mathrm{~h}$ followed by PBS washing for three times. Then, the bacterial concentration was adjusted to $1 \times 10^{8} \mathrm{CFU} / \mathrm{mL}$ and stored in the ice box before use. Nine female 000697-B6.BKS(D)-Leprdb/J diabetic defective mice (10-11 weeks, 50-55 g, GLU > $200 \mathrm{mg} / \mathrm{dL}$ ) fed with standard pellet diet and water were used. Our study was approved by the Institutional Animal Care and Use Committee of University of Nebraska Medical Center (protocol \#19-069-07-FC).

The biofilm was established in the 000697-B6.BKS(D)-Leprdb/J mouse excisional wounds. Two $6 \mathrm{~mm}$-diameter full-thickness wounds were created on the back of a mouse using a disposable biopsy punch (Integra Miltex, Kai Medical) and fixed with a wound splint (Grace Bio-labs, Inc., Bend, OR). The wounds were all inoculated with $10 \mu \mathrm{L}$ of $1 \times 10^{8} \mathrm{CFU} / \mathrm{mL}$ MRSA instantly after surgery, and $2 \%$ mupirocin was applied to treat the wounds at day 2 ( $24 \mathrm{~h}$ after surgery). Then, the surrounding and wound tissue was collected using a $10 \mathrm{~mm}-$ diameter punch, and the biofilm was confirmed by CFU count, LIVE/DEAD staining, and SEM observation.

After the establishment of biofilm-containing wound model, F127/W379-PCL-S core-shell nanofiber membranes or Janus-type dressings were placed on the wound, different strategies of dressing changes were applied to treat the biofilm. The wound and surrounding tissue was collected by a $10 \mathrm{~mm}$-diameter punch into sterilized tubes at different time points. Then, 1 $\mathrm{mL}$ of sterilized PBS was added in each tube, which was blended by a homogenizer.

Subsequently, the mixed liquid was diluted and plated on agar dishes. All the dishes were inoculated in a $37^{\circ} \mathrm{C}$ microbial incubator for $18 \mathrm{~h}$, and the $\mathrm{CFU}$ numbers were counted.

\section{P. aeruginosa/MRSA Blend Biofilm Formation and Anti-Biofilm Efficacy Test of Janus-Type Antimicrobial Dressings Ex Vivo.}

To further evaluate the anti-biofilm efficacy against biofilms composed multiple types of bacteria ex vivo, we established a $P$. aeruginosa/MRSA blend biofilm-containing wound model on human skin tissues. Briefly, a wound was generated as described above. MRSA and $P$. aeruginosa colonies were prepared. Then, $10 \mu \mathrm{L}$ of MRSA and $10 \mu \mathrm{L}$ of $P$. aeruginosa 
bacterial solution with the concentration of $1 \times 10^{8} \mathrm{CFU} / \mathrm{mL}$ were inoculated to the wound simultaneously. The culture was maintained at $37{ }^{\circ} \mathrm{C}$ for $72 \mathrm{~h}$. Then, the surrounding and wound tissues were collected, and the biofilm formation was confirmed by Gram staining, SEM observation, and CFU counting. For anti-biofilm efficacy test, dressings were placed on the wounds after the formation of $P$. aeruginosa/MRSA blend biofilms. The dressings were applied to treat the blend biofilm containing wounds and changed every $24 \mathrm{~h}$ for 3 times. After treatment, the wound and surrounding tissues were collected by a $10 \mathrm{~mm}$ diameter punch and put into sterilized tubes. Then, $1 \mathrm{~mL}$ of sterilized PBS was added to each tube, which was blended by a homogenizer (Fisher Scientific, Hampton, NH). Subsequently, the mixed liquid was diluted and plated on agar dishes. All the dishes were inoculated in a $37^{\circ} \mathrm{C}$ microbial incubator for $18 \mathrm{~h}$, and the $\mathrm{CFU}$ numbers were counted.

\section{Statistical Analysis.}

All the quantitative data are represented as mean \pm standard deviation. The obtained data were analyzed for statistical significance using one-way ANOVA tests and $* \mathrm{p}<0.05$ was considered statistically significant for all tests.

\section{Computational Simulations.}

COMSOL Multiphysics (COMSOL Inc., Burlington, MA, USA) was used to model the diffusion of peptide within the biofilm layer. To reduce the computational cost, the model was built based on the symmetries present in the patch matrix, simulating a quarter of a microneedle and considering the distance (d) between two adjacent microneedles as model width (w). The model consists of three domains: the patch (height $(\mathrm{h})=100 \mu \mathrm{m}, \mathrm{w}=225 \mu \mathrm{m}$ for $\mathrm{d}=150 \mu \mathrm{m}$ and $\mathrm{h}=100 \mu \mathrm{m}, \mathrm{w}=300 \mu \mathrm{m}$ for $\mathrm{d}=300 \mu \mathrm{m}$ ), the microneedle (radius $(\mathrm{r})=$ $150 \mu \mathrm{m}, \mathrm{h}=500 \mu \mathrm{m})$ and the biofilm layer $(\mathrm{h}=1000 \mu \mathrm{m}, \mathrm{w}=225 \mu \mathrm{m}$ for $\mathrm{d}=150 \mu \mathrm{m}$ and $\mathrm{h}$ $=1000 \mu \mathrm{m}, \mathrm{w}=300 \mu \mathrm{m}$ for $\mathrm{d}=300 \mu \mathrm{m}$ ). The 'transport of diluted species' physics was used to simulate the diffusion of peptides from the microneedle patch $(\mathrm{Mn})$ to the biofilm layer, considered as a homogeneous domain. The microneedle patch was considered as an infinite reservoir with a concentration of the peptide equal to $18.8 \mathrm{~mol} / \mathrm{m}^{3}$. Three different diffusion coefficients (D) for the biofilm layer were tested, namely $1 \times 10^{-12}, 5 \times 10^{-13}$ and $1 \times 10^{-13}$ $\mathrm{m}^{2} / \mathrm{s}$. To avoid a mass flux across the boundaries, a no-flux condition was set on top and bottom faces of the model and a symmetry condition was set on the lateral faces of the model. The initial concentration of peptides in the biofilm layer was set to 0 . A physicscontrolled mesh was used with an extremely fine element size. A time-dependent study was performed to simulate the diffusion of the peptides over a total time equal to $40 \mathrm{~h}$ and a time step equal to $0.25 \mathrm{~h}$. Three parallel planes were created to evaluate the peptide concentrations at different depths of the biofilm. The first (top) plane was located $250 \mu \mathrm{m}$ away from the patch basis, the second (middle) plane was located $500 \mu \mathrm{m}$ away from the patch basis in correspondence of the microneedle tip, and the third (bottom) plane was located $1000 \mu \mathrm{m}$ away from the patch basis in correspondence of the biofilm layer basis. A control model without the microneedle was built with the same dimensions of the patch and the same diffusion coefficients for the biofilm layer. 


\title{
Supplementary Material
}

Refer to Web version on PubMed Central for supplementary material.

\section{ACKNOWLEDGMENTS}

\begin{abstract}
This work was partially supported by startup funds from University of Nebraska Medical Center (UNMC), UNMC Regenerative Medicine Program pilot grant, NE LB606, National Institute of General Medical Science (NIGMS) of the National Institutes of Health (NIH) under Award Number R01GM123081 to JX, 1R01GM138552 to JX and GW, NIH grant R01AI105147 and Nebraska Research Initiative POC award to GW, and NIH grants R21EB026175, R21EB025270, R00CA201603, R01EB028143, R01GM134036 and the support by the Brigham Research Institute to YSZ. We thank Qianhui Wu to help cultivate the bacteria.
\end{abstract}

\section{REFERENCES}

(1). Sen CK; Gordillo GM; Roy S; Kirsner R; Lambert L; Hunt TK; Gottrup F; Gurtner GC; Longaker MT Human Skin Wounds: A Major and Snowballing Threat to Public Health and the Economy. Wound Repair Regen. 2009, 17, 763-771. [PubMed: 19903300]

(2). Sen CK Human Wounds and Its Burden: An Updated Compendium of Estimates. Adv. Wound Care 2019, 8, 39-48.

(3). Malone M; Bjarnsholt T; McBain AJ; James GA; Stoodley P; Leaper D; Tachi M; Schultz G; Swanson T; Wolcott RD The Prevalence of Biofilms in Chronic Wounds: A Systematic Review and Meta-Analysis of Published Data. J. Wound Care 2017, 26, 20. [PubMed: 28103163]

(4). Hall CW; Mah TF Molecular Mechanisms of Biofilm-Based Antibiotic Resistance and Tolerance in Pathogenic Bacteria. FEMS Microbiol. Rev 2017, 41, 276-301. [PubMed: 28369412]

(5). Balcazar JL; Subirats J; Borrego CM The Role of Biofilms as Environmental Reservoirs of Antibiotic Resistance. Front. Microbiol 2015, 6, 1216. [PubMed: 26583011]

(6). Stewarts PS Diffusion in Biofilms. J. Bacteriol 2003, 185, 1485-1491. [PubMed: 12591863]

(7). Costerton JW; Stewart PS; Greenberg EP Bacterial Biofilms: A Common Cause of Persistent Infections. Science 1999, 284, 1318-1322. [PubMed: 10334980]

(8). Stewarts PS Mechanisms of Antibiotic Resistance in Bacterial Biofilms. Int. J. Med. Microbiol 2002, 292, 107-113. [PubMed: 12195733]

(9). Bjamsholt T; Eberlein T; Malone M; Schultz G Management of Wound Biofilm. Wounds International 2017, 8, 1-6.

(10). Gompelman M; van Asten SA; Peters EJ Update on the Role of Infection and Biofilms in Wound Healing: Pathophysiology and Treatment. Plast. Reconstr. Surg 2016, 138, 61S-70S. [PubMed: 27556776]

(11). De Miguel I; Prieto I; Albornoz A; Sanz V; Weis C; Turon P; Quidant R Plasmon-Based Biofilm Inhibition on Surgical Implants. Nano Lett. 2019, 19, 2524-2529. [PubMed: 30860848]

(12). Teirlinck E; Xiong R; Brans T; Forier K; Fraire J; Acker HV; Matthijs N; Rycke RD; De Smedt SC; Coenye T; Braeckmans K Laser-Induced Vapour Nanobubbles Improve Drug Diffusion and Efficiency in Bacterial Biofilms. Nat. Commun 2018, 9, 4518. [PubMed: 30375378]

(13). Quan K; Zhang Z; Chen H; Ren X; Ren Y; Peterson BW; van der Mei HC; Busscher HJ Artificial Channels in an Infectious Biofilm Created by Magnetic Nanoparticles Enhanced Bacterial Killing by Antibiotics. Small 2019,15, 1902313.

(14). Xu J; Danehy R; Cai H; Zheng A; Pu M; Nusawardhana A; Rowe-Magnus D; Guo F Microneedle Patch-Mediated Treatment of Bacterial Biofilms. ACS Appl. Mater. Interfaces 2019, 11, 14640-14646. [PubMed: 30933463]

(15). Permana AD; Mir M; Utomo E; Donnelly RF Bacterially Sensitive Nanoparticle-Based Dissolving Microneedles of Doxycycline for Enhanced Treatment of Bacterial Biofilm Skin Infections: A Proof of Concept Study. Int. J. Pharm 2020, DOI: 10.1016/j.ijpx.2020.100047.

(16). Caffarel-Savador E; Kearney M; Mairs R; Gallo L; Stewart SA; Brady AJ; Donnelly RF Methylene Blue-Loaded Dissolving Microneedles: Potential Use in Photodynamic Antimicrobial Chemotherapy of Infected Wounds. Pharmaceutics 2015, 7, 397-412. [PubMed: 26426040] 
(17). Chi J; Zhang X; Chen G; Shao C; Zhao Y; Wang Y Antibacterial and Angiogenic Chitosan Microneedle Array Patch for Promoting Wound Healing. Bioact. Mater 2020, 5, 253-259. [PubMed: 32128464]

(18). Frydman GH; Olaleye D; Annamalai D; Layne K; Yang I; Kaafarani HMA; Fox JG Manuka Honey Microneedles for Enhanced Wound Healing and the Prevention and/or Treatment of Methicillin-Resistant Staphylococcus aureus (MRSA) Surgical Site Infection, Sci. Rep 2020, 10, 13229. [PubMed: 32764604]

(19). Wang G Improved Methods for Classification, Prediction, and Design of Antimicrobial Peptides. Methods Mol. Biol 2015, 1266, 43-66.

(20). Durr UHN; Sudheendra US; Ramamoorthy A LL-37, the Only Human Member of the Cathelicidin Family of Antimicrobial Peptides. Biochim. Biophys. Acta 2006, 1758, 1408-1425. [PubMed: 16716248]

(21). Li X; Li Y; Han H; Miller DW; Wang G Solution Structures of Human LL-37 Fragments and NMR-based Identification of a Minimal Membrane-Targeting Antimicrobial and Anticancer Region. J. Am. Chem. Soc 2006, 128, 5776-5785. [PubMed: 16637646]

(22). Mishra B; Wang G Individual and Combined Effects of Engineered Peptides and Antibiotics on Pseudomonas aeruginosa Biofilms. Pharmaceuticals 2017, 10, 58.

(23). Wang G; Hanke ML; Mishra B; Lushnikova T; Heim CE; Thomas VC; Bayles KW; Kielian T Transformation of Human Cathelicidin LL-37 into Selective, Stable, and Potent Antimicrobial Compounds. ACS Chem. Biol 2014, 9, 1997-2002. [PubMed: 25061850]

(24). Mishra B; Golla RM; Lau K; Lushnikova T; Wang G Anti-Staphylococcal Biofilm Effects of Human Cathelicidin Peptides. ACS. Med. Chem. Lett 2016, 7, 117-121. [PubMed: 26819677]

(25). Su Y; Wang H; Mishra B; Narayana JL; Jiang J; Reilly DA; Hollins RR; Carlson MA; Wang G; Xie J Nanofiber Dressings Topically Delivering Molecularly Engineered Human Cathelicidin Peptides for the Treatment of Biofilms in Chronic Wounds. Mol. Pharm 2019, 16, 2011-2020. [PubMed: 30916573]

(26). Wang G Structure of Human Host Defense Cathelicidin LL-37 and Its Smallest Antimicrobial Peptide KR-12 in Lipid Micelles. J. Biol. Chem 2008, 283, 32637-32643. [PubMed: 18818205]

(27). Wang G; Li X; Wang Z APD3: The Antimicrobial Peptide Database as a Tool for Research and Education. Nucleic Acids Res. 2016, 44, D1087. [PubMed: 26602694]

(28). Mishra B; Narayana JL; Lushnikova T; Wang X; Wang G Local Cationicity is Important for Systemic In Vivo Efficacy of Database-Derived Peptides against Drug-Resistant Gram-Positive Pathogens. Proc. Natl. Acad. Sci. USA 2019, 116, 13517-13522. [PubMed: 31209048]

(29). Narayana JL; Mishra B; Lushnikova T; Wu Q; Chhonker YS; Zhang Y, Zarena D; Salnikov E; Dang X; Wang F; Murphy C; Foster KW; Gorantla S; Bechinger B; Murry DJ; Wang G Two Distinct Amphipathic Peptide Antibiotics with Systemic Efficacy. Proc. Natl. Acad. Sci. USA 2020, 117, 19446-19454. [PubMed: 32723829]

(30). Pierre MB; Rossetti FC Microneedle-Based Drug Delivery Systems for Transdermal Route. Curr. Drug Targets 2014, 15, 281-291. [PubMed: 24144208]

(31). Bariya SH; Gohel MC; Mehta TA; Sharma OP Microneedles: An Emerging Transdermal Drug Delivery System. J. Pharm. Pharmacol 2012, 64, 11-29. [PubMed: 22150668]

(32). Prausnitz MR Microneedles for Transdermal Drug Delivery. Adv. Drug Del. Rev 2004, 56, 581587.

(33). Lee JW; Prausnitz MP Drug Delivery Using Microneedle Patches: Not Just for Skin, Expert Opin. Drug Del 2018, 15, 541-543.

(34). Woodruff MA; Hutmacher DW The Return of a Forgotten Polymer-Polycaprolactone in the 21st Century. Prog. Polym. Sci 2010, 35, 1217-1256.

(35). Buhler V Polyvinylpyrrolidone Excipients for Pharmaceuticals: Povidone, Crospovidone and Copovidone, New York: Springer, Heidelberg, Berlin, 2005.

(36). Buch PJ; Chai Y; Goluch ED Treating Polymicrobial Infections in Chronic Diabetic Wounds. Clin. Microbio. Rev 2019, 32, e00091-18.

(37). Dowd SE; Wolcott RD; Sun Y; McKeehan T; Smith E; Rhoads D Polymicrobial Nature of Chronic Diabetic Foot Ulcer Biofilm Infections Determined Using Bacterial Tag Encoded FLX Amplicon Pyrosequencing (bTEFAP). PLoS One 2008, 3, e3326. [PubMed: 18833331] 
(38). Lawrence JR; Wolfaardt GM; Korber DR Determination of Diffusion Coefficients in Biofilms by Confocal Laser Microcopy. Appl. Environ. Microbiol 1994, 60, 1166-1173. [PubMed: 16349228]

(39). Cao B; Christophersen L; Kolpen M; Jensen PO; Sneppen K; Hoiby B; Moser C; Sams T Diffusion Retardation by Binding of Tobramycin in an Alginate Biofilm Model. PLoS One 2016, 11, e0153616. [PubMed: 27100887]

(40). Stewart PS Theoretical Aspects of Antibiotic Diffusion into Microbial Biofilms. Antimicrob. Agents Chemother 1996, 40, 2517-2522. [PubMed: 8913456]

(41). Parsek MR; Singh PK Bacterial Biofilms: An Emerging Link to Disease Pathogenesis. Annu. Rev. Microbiol 2003, 57, 677-701. [PubMed: 14527295]

(42). Martin C; Low WL; Gupta A; Amin MCIM; Radecka I; Britland ST; Raj P; Kenward KM A. Strategies for Antimicrobial Drug Delivery to Biofilm. Curr. Pharm. Des 2015, 21, 43-66. [PubMed: 25189862]

(43). Morones-Ramirez JR; Winkler JA; Spina CS; Collins JJ Silver Enhances Antibiotic Activity Against Gram-Negative Bacteria. Sci. Translat. Med 2013, 5, $190 \mathrm{ra} 81$.

(44). Meeker DG; Jenkins SV; Miller EK; Beenken KE; Loughran AJ; Powless A; Muldoon TJ; Galanzha EI; Zharov VP; Smeltzer MS; Chen J Synergistic Photothermal and Antibiotic Killing of Biofilm-Associated Staphylococcus aureus Using Targeted Antibiotic-Loaded Gold Nanostructs. ACS Infec. Dis 2016, 2, 241-250. [PubMed: 27441208]

(45). Li M; Li L; Su K; Liu X; Zhang T; Liang Y; Jing D; Yang X; Zheng D; Cui Z; Li Z; Zhu S; Yeung KWK; Zheng Y; Wang X; Wu S Highly Effective and Noninvasive Near-Infrared Eradication of a Staphylococcus aureus Biofilm on Implants by a Photoresponsive Coating within 20 min. Adv. Sci. (Weinh) 2019, 6, 1900599. [PubMed: 31508278]

(46). Chen S; Wang H; McCarthy A; Yan Z; Kim HJ; Carlson MA; Xia Y; Xie J Three-Dimensional Objects Consisting of Hierarchically Assembled Nanofibers with Controlled Alignments for Regenerative Medicine. Nano Lett. 2019, 19, 2059-2065. [PubMed: 30788971] 
A

B

\section{Hydrophilic}
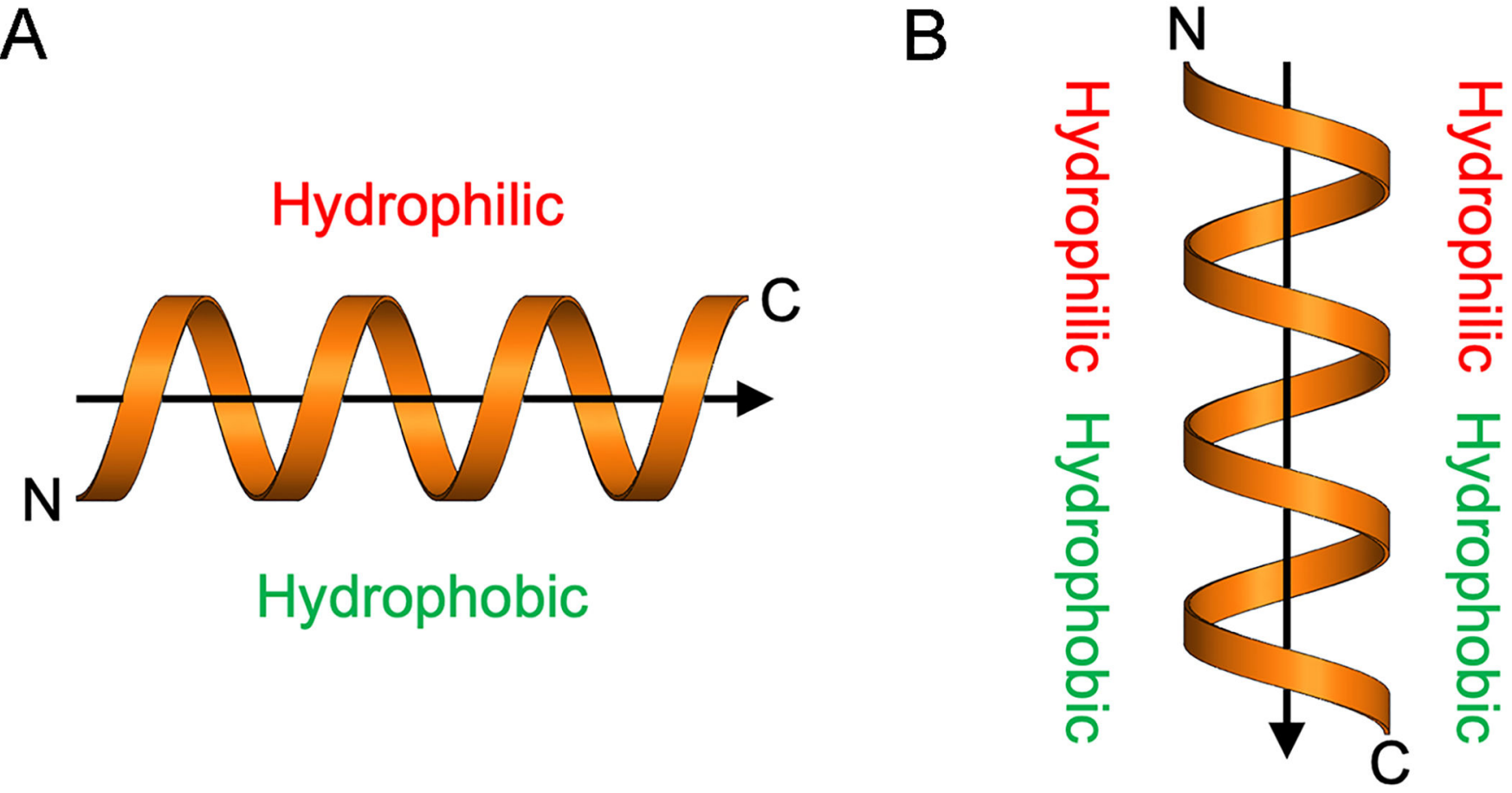

Figure 1.

Two amphipathic models for cationic antimicrobial peptides. (A) Cartoon A represents the classic amphipathic helix model, where the hydrophilic and hydrophobic amino acids are distributed above and below the helix backbone. This model is common in nature. (B) A different amphipathic model where the hydrophilic and hydrophobic amino acids are clustered in two sectors. This model is rarely observed in nature. In both models, it is assumed that the hydrophobic surface is responsible for targeting bacterial membranes. 


\section{Nanofiber membrane}

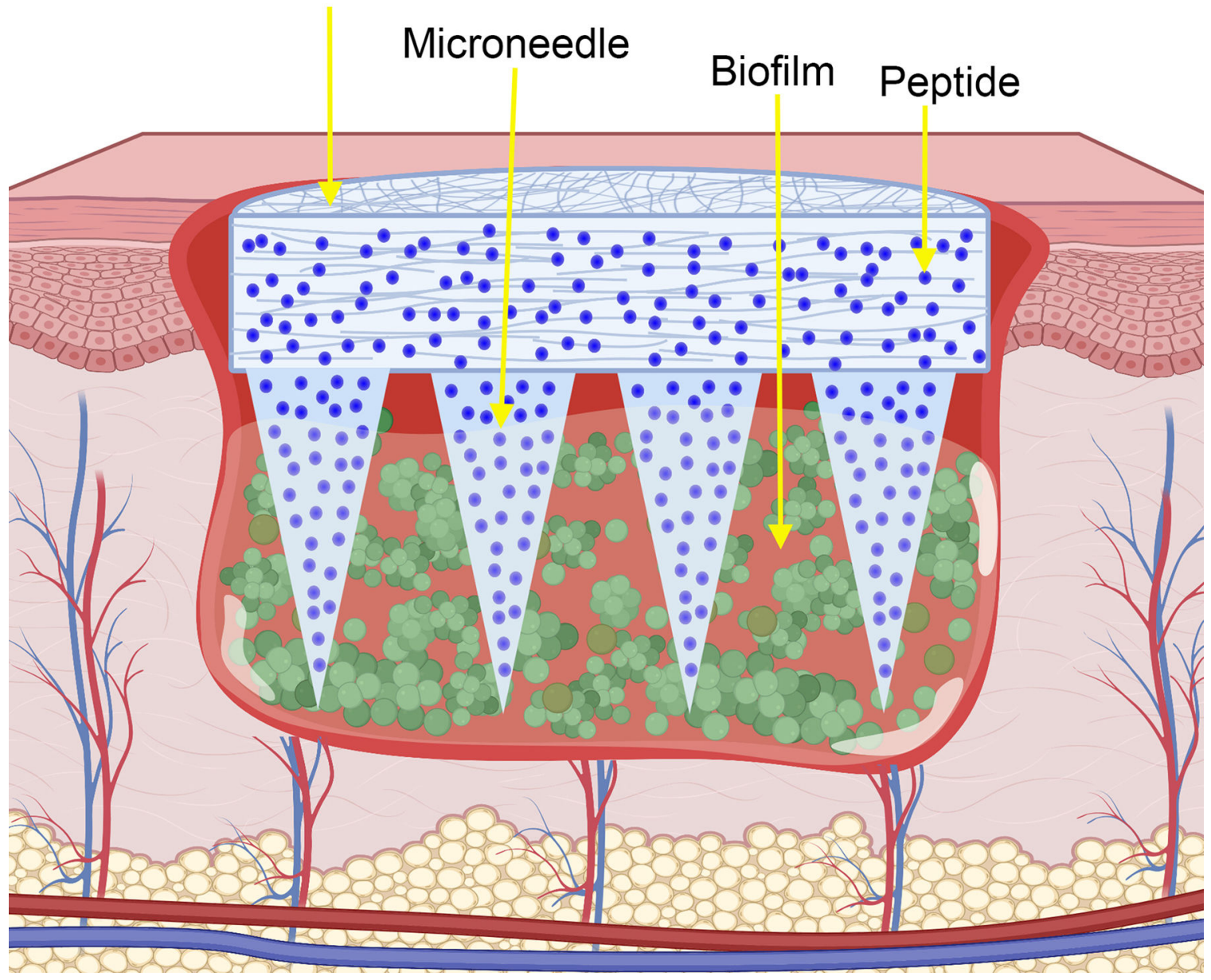

Figure 2.

Schematic illustrating Janus-type antimicrobial dressings consisting of molecularly engineered peptide-loaded electrospun nanofiber membranes and microneedle arrays for the treatment of biofilms in chronic wounds. 

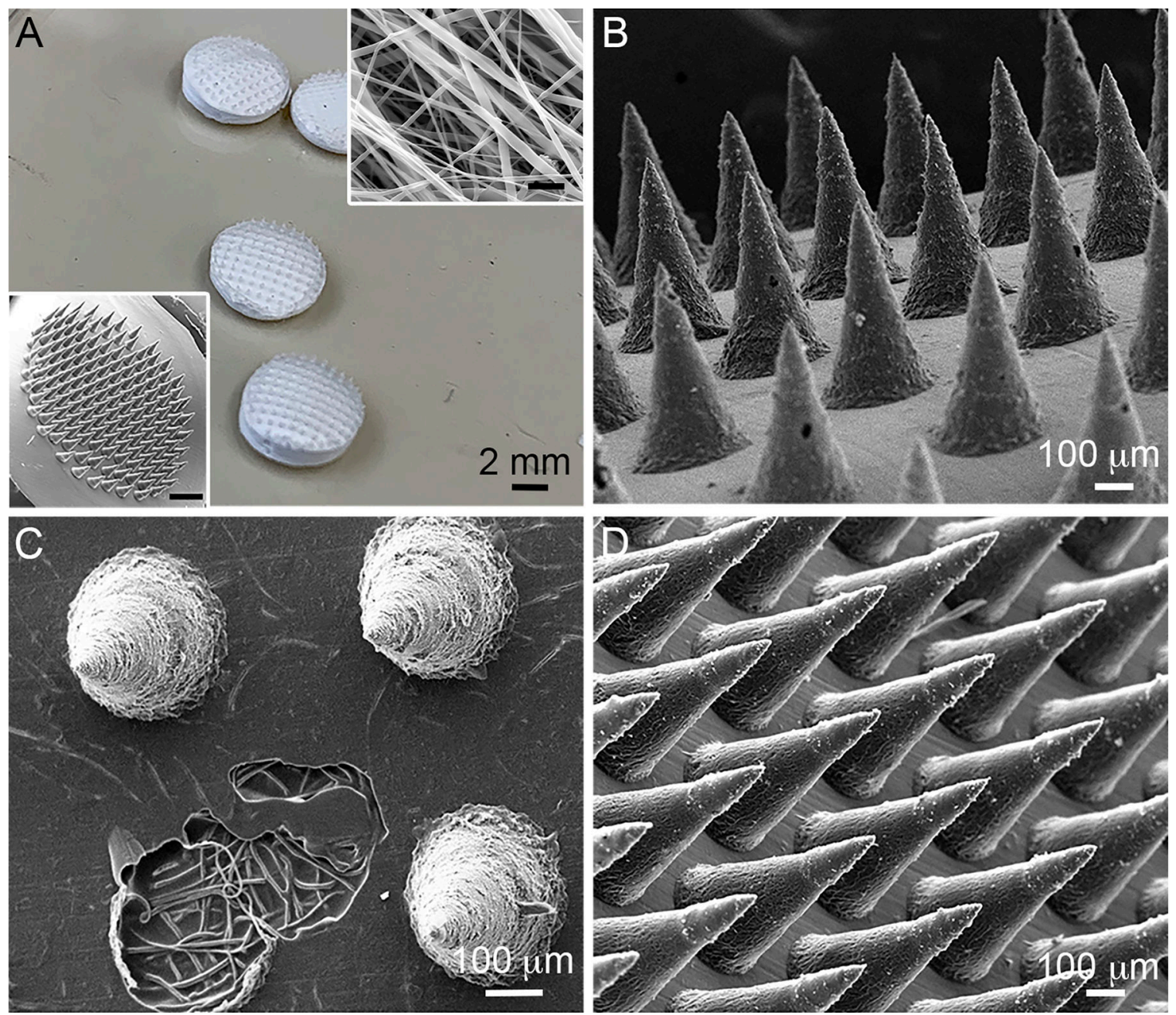

Figure 3. Janus-type dressings.

(A) Photo showing a Janus-type dressing. Inset (left bottom): SEM image showing the whole view of a microneedle array immobilized on the surface of nanofiber membrane. Scale bar $=1 \mathrm{~mm}$. Inset (right up): SEM image showing the electrospun nanofiber substrate. Scale bar $=5 \mu \mathrm{m}$. (B) SEM image showing peptides containing dissolvable microneedle arrays on nanofiber membranes (100 microneedles per membrane). (C) SEM image showing magnified image of (B) and one microneedle was intentionally removed to reveal the nanofiber matrices underneath. (D) SEM image showing peptides containing dissolvable microneedle arrays on nanofiber membranes (150 microneedles per membrane). 
$A$ PCL-F127
$\square$ PCL-F127/W379+aqueous W379

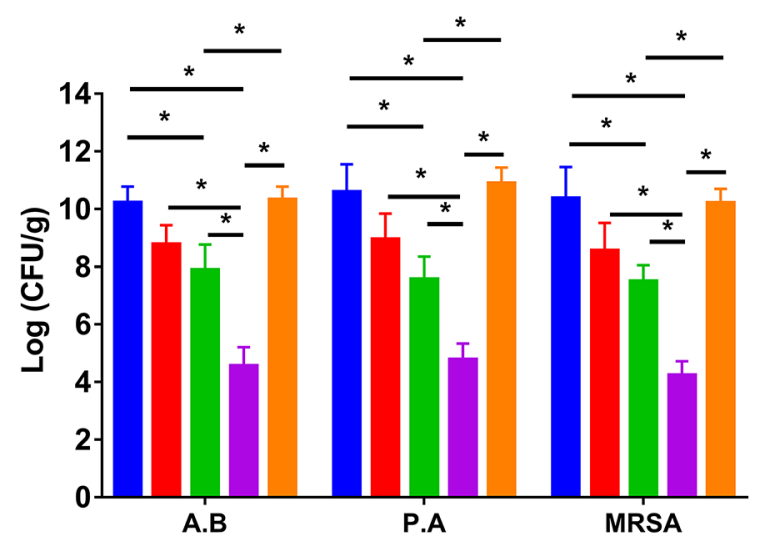

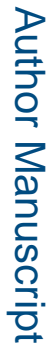

을

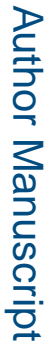
containing human skin wound model. treatment to the wounds.
B

PCL-F127 PCL-F127/W379 without treatment PCL-F127/W379+aqueous W379 PCL-F127/W379+PVP/W379 MN

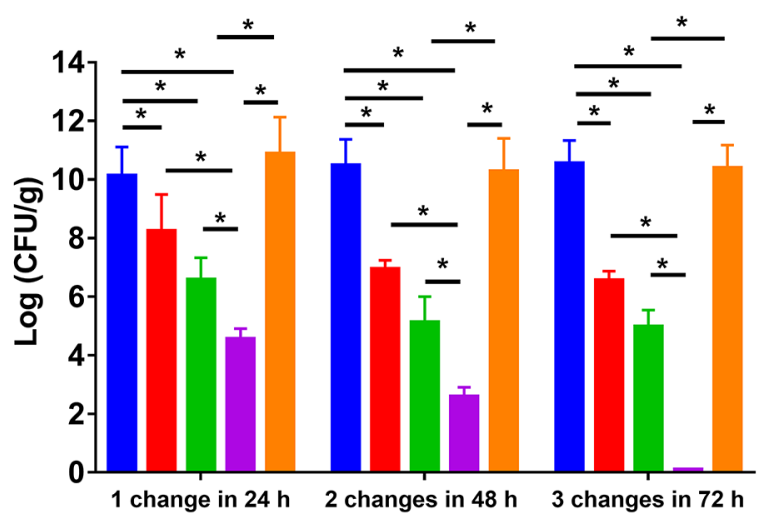

D $\square$ PCL-F127 PCL-F127/W379 without treatment PCL-F127/W379+aqueous W379 PCL-F127/W379+PVP/W379 MN

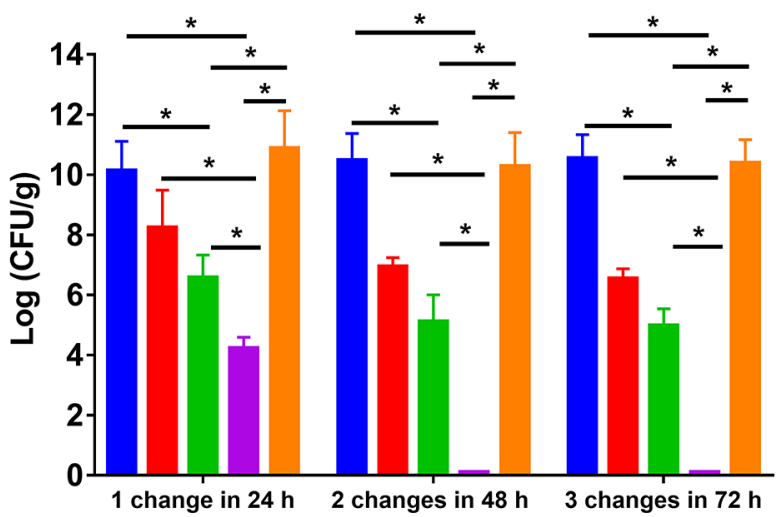

Figure 4. Biofilm treatment efficacy of Janus-type antimicrobial dressings in an ex vivo biofilm-

(A) The Janus-type dressing was not changed within $24 \mathrm{~h}$ against three different pathogens.

(B) Different dressing changes against MRSA biofilm. (C) Double the peptide concentrations in microneedles against MRSA biofilm. (D) High density microneedles in Janus-type dressings against MRSA biofilm. (*p<0.05) PCL-F127: PCL-F127 nanofibers. PCL-F127/W379: W379 peptide-loaded PCL-F127 nanofibers. PCL-F127/W379+aqueous W379: W379 peptide-loaded PCL-F127 nanofibers + free W379 peptides. PCL-F127/ W379+PVP/W379 MN: Janus-type dressing composed of W379 peptide-loaded PCL-F127 nanofiber membrane and W379 peptide-loaded microneedle arrays. Without treatment: no 

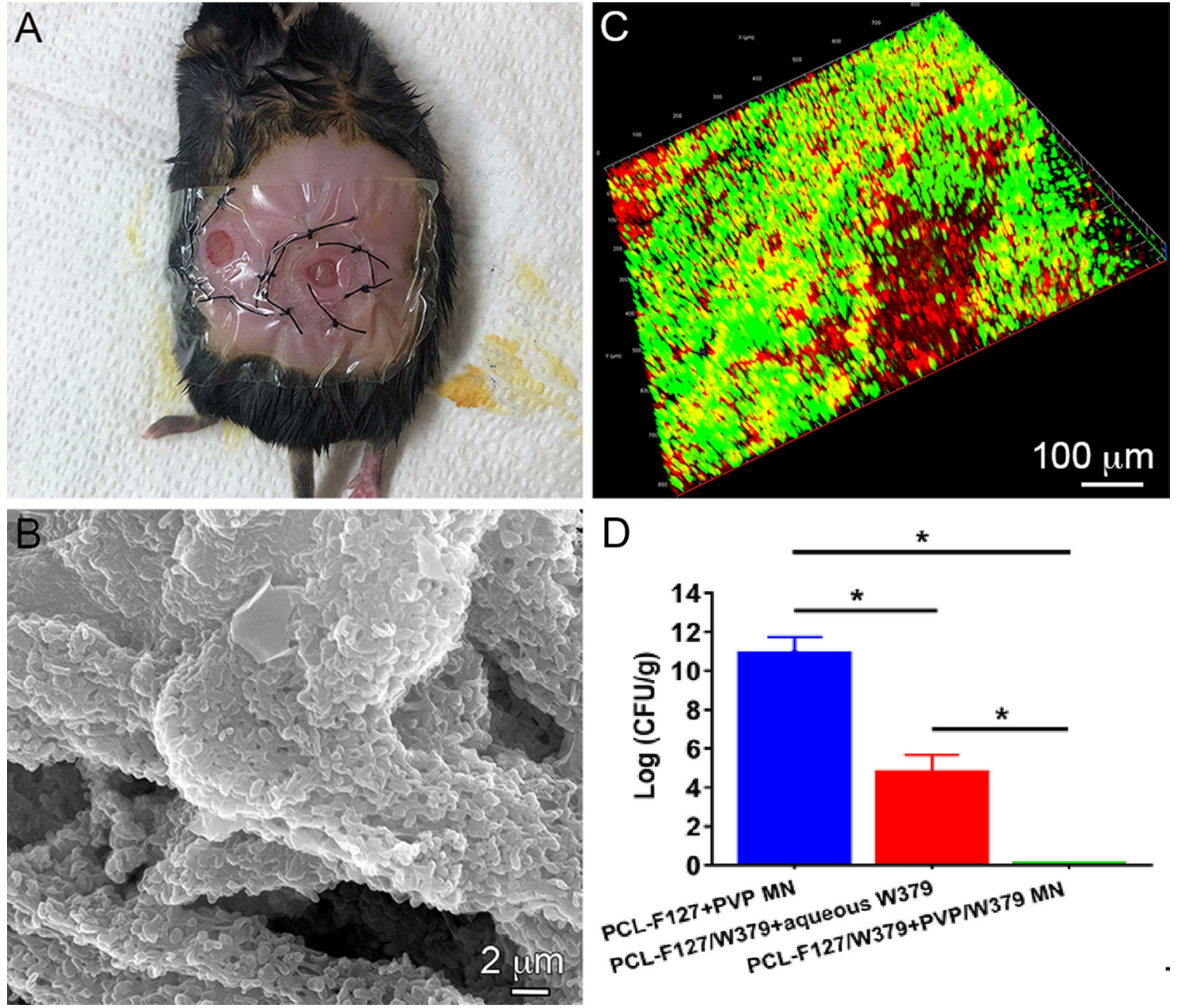

Figure 5. Biofilm formation in type II diabetic mice wound and anti-biofilm efficacy test of Janus-type antimicrobial dressings.

(A) Wounds were created and fixed with a splint, and MRSA was inoculated for $24 \mathrm{~h}$. (B) LIVE/DEAD staining for the tissue collected from wounds after $24 \mathrm{~h}$ of MRSA inoculation and subsequent $24 \mathrm{~h} 2 \%$ mupirocin treatment. (C) SEM observation of the tissue collected from wounds after $24 \mathrm{~h}$ of MRSA inoculation and subsequent $24 \mathrm{~h} 2 \%$ mupirocin treatment. (D) The anti-biofilm efficacy of Janus-type antimicrobial dressings in vivo. The dressings were changed every $24 \mathrm{~h}$ for 3 times. (*p < 0.05) PCL-F127+PVP MN: W379 peptideloaded PCL-F127 nanofibers + PVP microneedle arrays without W379 peptide loading. PCL-F127/W379+aqueous W379: W379 peptide-loaded PCL-F127 nanofibers + free W379 peptides. PCL-F127/W379+PVP/W379 MN: Janus-type dressing composed of W379 peptide-loaded PCL-F127 nanofiber membrane and W379 peptide-loaded microneedle arrays. 

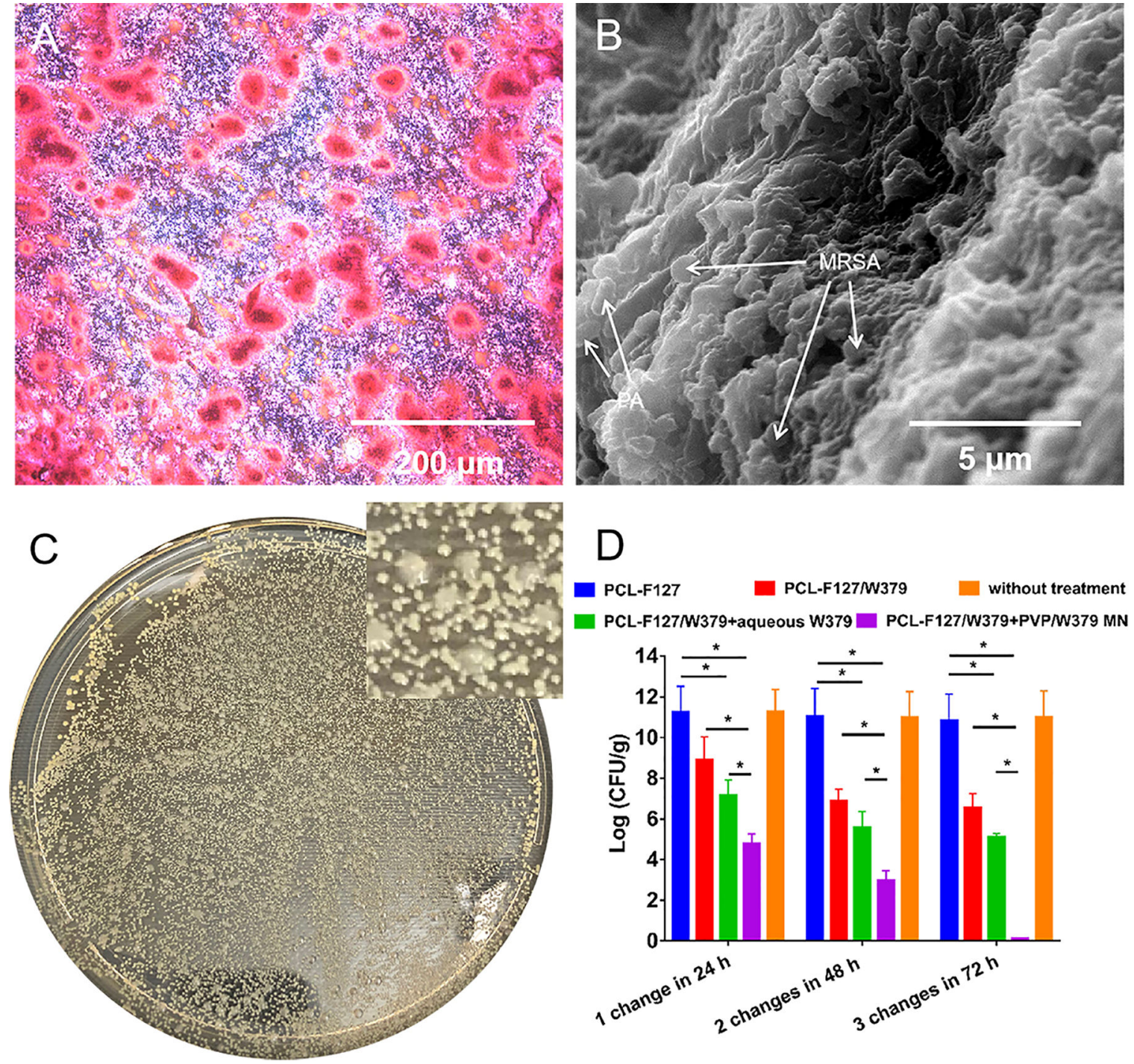

Figure 6. P. aeruginosa/MRSA blend biofilm formation and anti-biofilm efficacy test in an ex vivo human skin wound model.

(A) Gram staining of $P$. aeruginosa (Gram-, red)/MRSA (Gram+, violet) blend biofilm established in an ex vivo human skin wound model by co-inoculation of two types of bacteria strains for $72 \mathrm{~h}$. (B) SEM observation of the tissue collected from wounds after $72 \mathrm{~h}$ of $P$. aeruginosa and MRSA co-inoculation. PA: $P$. aeruginosa (C) Colonial morphologies of $P$. aeruginosa and MRSA. The smaller colonies in golden or yellow color were MRSA colonies, while the bigger colonies in lighter color were $P$. aeruginosa. (D) The anti-biofilm efficacy of Janus-type antimicrobial dressings against blend biofilms in ex vivo. The dressings were changed every $24 \mathrm{~h}$ for 3 times. PCL-F127: PCL-F127 nanofibers. PCLF127/W379: W379 peptides loaded PCL-F127 nanofibers. PCL-F127/W379+aqueous W379: W379 peptides loaded PCL-F127 nanofibers + free W379 peptides. PCL-F127/ W379+PVP/W379 MN: Janus-type dressing composed of W379 peptides loaded PCL-F127 nanofiber membrane and W379 peptide-loaded microneedle arrays. Without treatment: no treatment to the wounds. 

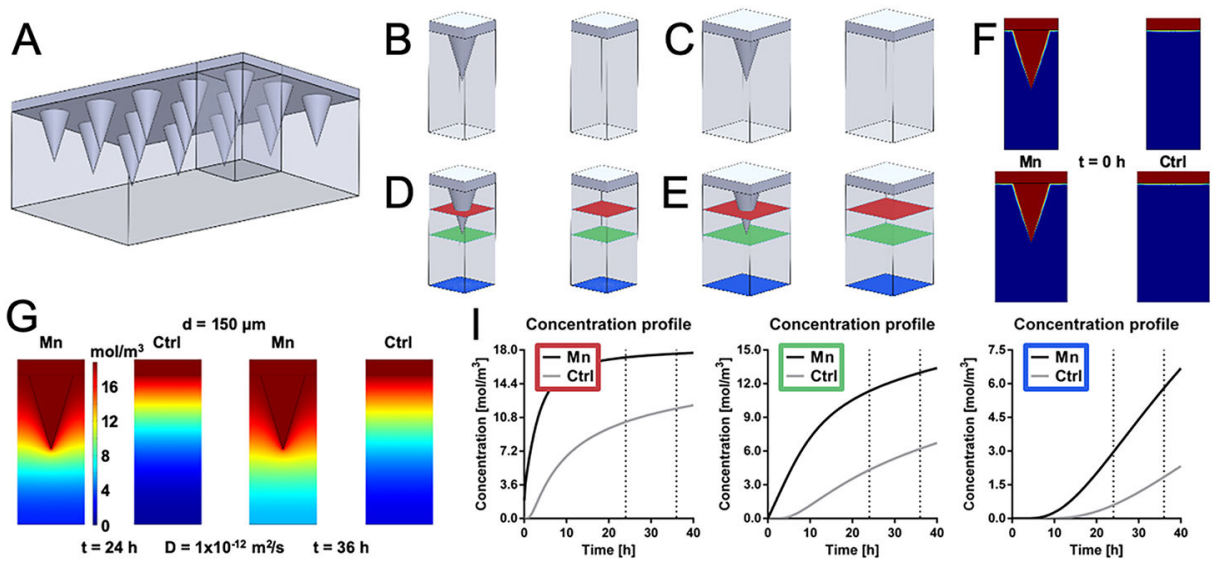

Concentration profile

Concentration profile
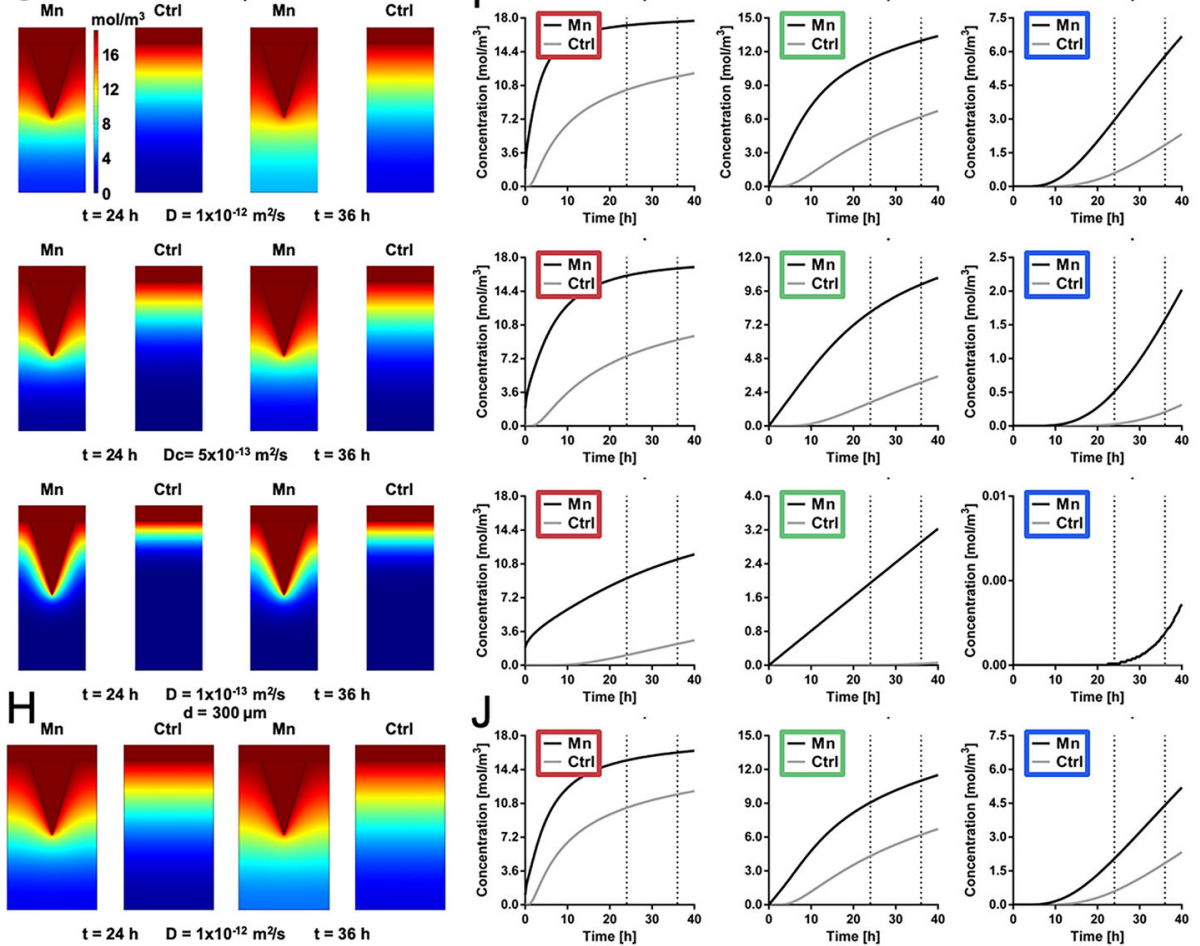

$\mathrm{J}$
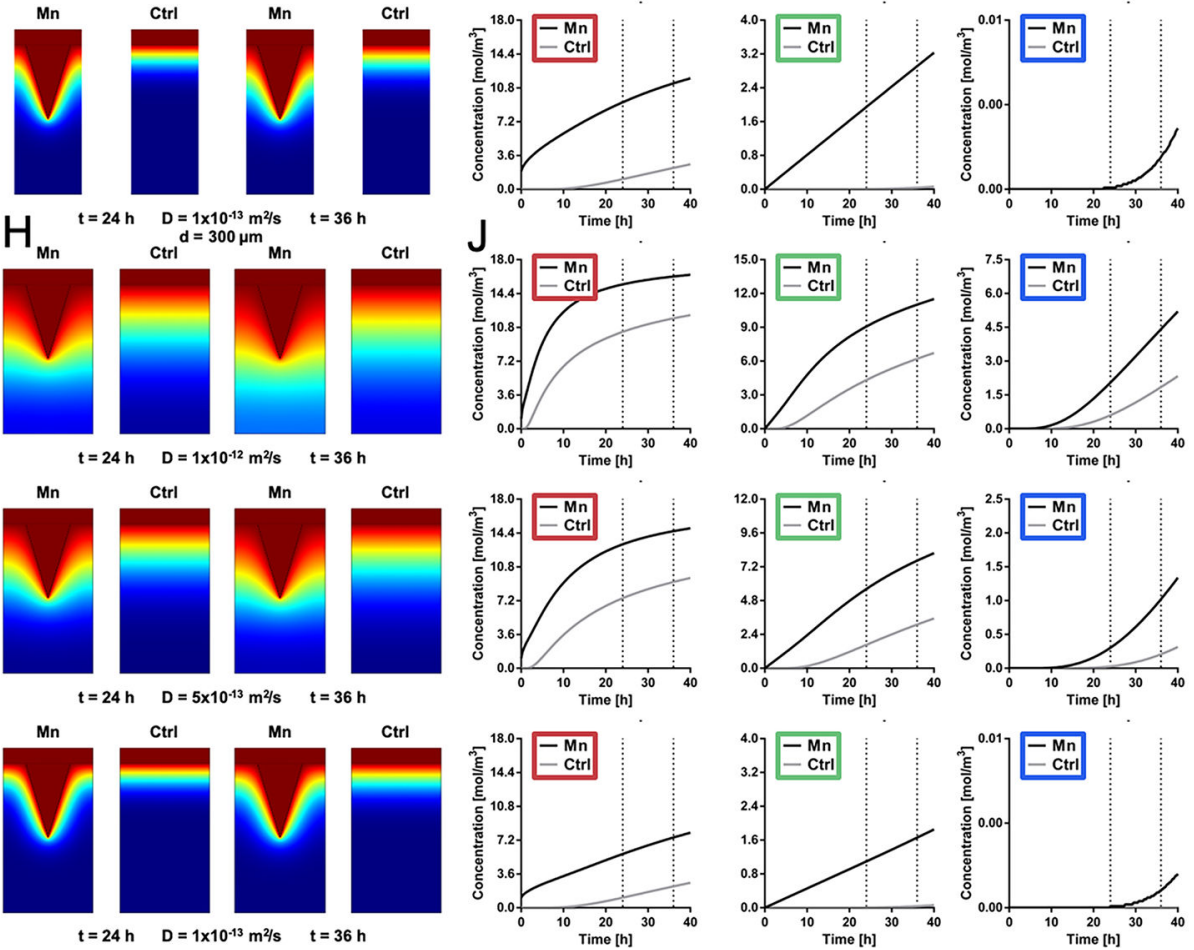

Figure 7. Computational simulations.

(A-C) A CAD model of the microneedle patch (A) was used to build single microneedle models $(\mathrm{Mn})$ and control models $(\mathrm{Ctrl})$ considering the distances d between two adjacent microneedles equal to $150 \mu \mathrm{m}$ (B) and $300 \mu \mathrm{m}$ (C). (D, E) Three parallel planes (top-red, middle-green and bottom-blue) were used for the evaluation of the peptide concentrations at different depths of the biofilm. (F-H) The color maps of the peptide concentrations were obtained at the beginning of the diffusion $(\mathrm{F})$ and after $24 \mathrm{~h}$ and $36 \mathrm{~h}$ for different diffusion coefficients and distances between microneedles $(\mathrm{G}, \mathrm{H})$. (I, J) The concentration profiles of 
the peptide along time were obtained in correspondence of top, middle and bottom planes for different diffusion coefficients and distances between microneedles. 